\title{
Determination of the atmospheric lifetime and global warming potential of sulfur hexafluoride using a three-dimensional model
}

\author{
Tamás Kovács $^{1}$, Wuhu Feng ${ }^{1,2}$, Anna Totterdill ${ }^{1}$, John M. C. Plane ${ }^{1}$, Sandip Dhomse ${ }^{2}$, Juan Carlos Gómez-Martín ${ }^{1}$, \\ Gabriele P. Stiller ${ }^{3}$, Florian J. Haenel ${ }^{3}$, Christopher Smith ${ }^{4}$, Piers M. Forster ${ }^{2}$, Rolando R. García ${ }^{5}$, Daniel R. Marsh ${ }^{5}$, \\ and Martyn P. Chipperfield ${ }^{2}$ \\ ${ }^{1}$ School of Chemistry, University of Leeds, Leeds, LS2 9JT, UK \\ ${ }^{2}$ NCAS, School of Earth and Environment, University of Leeds, Leeds, LS2 9JT, UK \\ ${ }^{3}$ Karlsruhe Institute of Technology, IMK-ASF, PO BOX 3640, 76021 Karlsruhe, Germany \\ ${ }^{4}$ Energy Research Institute, School of Chemical and Process Engineering, University of Leeds, Leeds, LS2 9JT, UK \\ ${ }^{5}$ National Center for Atmospheric Research (NCAR), Boulder, Colorado, USA \\ Correspondence to: Martyn P. Chipperfield (m.chipperfield@leeds.ac.uk)
}

Received: 26 July 2016 - Published in Atmos. Chem. Phys. Discuss.: 18 August 2016

Revised: 6 December 2016 - Accepted: 19 December 2016 - Published: 20 January 2017

\begin{abstract}
We have used the Whole Atmosphere Community Climate Model (WACCM), with an updated treatment of loss processes, to determine the atmospheric lifetime of sulfur hexafluoride $\left(\mathrm{SF}_{6}\right)$. The model includes the following $\mathrm{SF}_{6}$ removal processes: photolysis, electron attachment and reaction with mesospheric metal atoms. The Sodankylä Ion Chemistry (SIC) model is incorporated into the standard version of WACCM to produce a new version with a detailed $D$ region ion chemistry with cluster ions and negative ions. This is used to determine a latitude- and altitudedependent scaling factor for the electron density in the standard WACCM in order to carry out multi-year $\mathrm{SF}_{6}$ simulations. The model gives a mean $\mathrm{SF}_{6}$ lifetime over an 11year solar cycle $(\tau)$ of 1278 years (with a range from 1120 to 1475 years), which is much shorter than the currently widely used value of 3200 years, due to the larger contribution $(97.4 \%)$ of the modelled electron density to the total atmospheric loss. The loss of $\mathrm{SF}_{6}$ by reaction with mesospheric metal atoms $(\mathrm{Na}$ and $\mathrm{K})$ is far too slow to affect the lifetime. We investigate how this shorter atmospheric lifetime impacts the use of $\mathrm{SF}_{6}$ to derive stratospheric age of air. The age of air derived from this shorter lifetime $\mathrm{SF}_{6}$ tracer is longer by $9 \%$ in polar latitudes at $20 \mathrm{~km}$ compared to a passive $\mathrm{SF}_{6}$ tracer. We also present laboratory measurements of the infrared spectrum of $\mathrm{SF}_{6}$ and find good agreement with previous studies. We calculate the resulting radiative forcings and efficiencies to be, on average, very similar to those re-
\end{abstract}

ported previously. Our values for the 20-, 100- and 500-year global warming potentials are 18000,23800 and 31300 , respectively.

\section{Introduction}

Sulfur hexafluoride $\left(\mathrm{SF}_{6}\right)$ is an anthropogenic greenhouse gas which is mainly used as an electrical insulator, with other applications as a quasi-inert gas. Although its main sources are in the Northern Hemisphere, its atmospheric abundance is increasing globally in response to these emissions and its long atmospheric lifetime (defined as the ratio of the atmospheric burden of a trace gas to its rate of loss from the atmosphere). $\mathrm{SF}_{6}$ is characterized by large absorption cross sections for terrestrial infrared radiation such that the presently increasing $\mathrm{SF}_{6}$ abundance will contribute a positive radiative forcing over many centuries. The important known removal sources are electron attachment and photolysis. Recently, Totterdill et al. (2015) have also measured bimolecular rate constants for the reaction of $\mathrm{SF}_{6}$ with mesospheric metals.

Harnisch and Eisenhauer (1998) reported that $\mathrm{SF}_{6}$ is naturally present in fluorites, and outgassing from these materials leads to a natural background atmospheric abundance of $0.01 \mathrm{pptv}$. However, at present the anthropogenic emissions of $\mathrm{SF}_{6}$ exceed the natural ones by a factor of 1000 or more 
and are responsible for the rapid increase in its atmospheric abundance. Surface measurements show that atmospheric $\mathrm{SF}_{6}$ has increased steadily since the 1980s (Geller et al., 1997; Maiss and Brenninkmeijer, 1998) and is still increasing fairly linearly. The current global mean surface mixing ratio is $8.60 \mathrm{pptv}$, which is increasing by about $0.33 \mathrm{pptv} \mathrm{yr}^{-1}$ ( $\sim 4 \% \mathrm{yr}^{-1}$; Dlugokencky et al., 2016).

$\mathrm{SF}_{6}$ provides a useful tracer of atmospheric transport in both the troposphere and stratosphere. Rates for transport of pollutants into, within and out of the stratosphere are important parameters that regulate stratospheric composition. The basic characteristics of the stratospheric BrewerDobson circulation (BDC) are known from observations of trace gases such as $\mathrm{SF}_{6}$ : air enters the stratosphere at the tropical tropopause, rises at tropical latitudes, and descends at middle and high latitudes to return to the troposphere. Understanding the rate of this transport on a global scale is crucial in order to predict the response of stratospheric ozone to climatic or chemical change. $\mathrm{SF}_{6}$ is essentially inert in the troposphere to middle stratosphere and is removed by electron attachment and photolysis in the upper stratosphere and mesosphere (Ravishankara et al., 1993). This tracer therefore provides an ideal probe of transport on timescales of importance in the stratospheric circulation and quantitative information on mean air mass age for the lower and middle stratosphere.

The mean age of air (AoA) is the interval between the time when the volume mixing ratio of a linearly increasing atmospheric tracer reaches a certain value at a given location in the stratosphere and an earlier time when this mixing ratio was reached at a reference location. Mean AoA is expressed as (Hall and Plumb, 1994; Waugh and Hall, 2002)

$\mathrm{AoA}=t(\chi, l, z)-t\left(\chi, l_{0}, z_{0}\right)$,

where $t$ is time, $\chi$ is the volume mixing ratio, $l$ and $z$ are latitude and altitude, and the 0 subscripts denote the reference latitude and altitude, which are chosen to be the upper tropical troposphere (for the purposes of our simulations we chose the grid point latitude $=1^{\circ} \mathrm{N}$, altitude $=13.9 \mathrm{~km}$ ). In principle the trend of AoA can be used to diagnose changes in the strength of the Brewer-Dobson circulation (BDC); in practice, however, it is very difficult to obtain unambiguous results on trends from this or any other trace gas (Garcia et al., 2011). Ideally, AoA should be determined experimentally using a tracer with a very small (or zero) chemical sink in the stratosphere or mesosphere. Otherwise, a correction must be applied to account for this loss. A correction would also be necessary for any non-linear tropospheric growth. However, for the period considered for diagnosing age of air in this paper (2002-2007), the growth of $\mathrm{SF}_{6}$ is approximately linear, so we can reasonably neglect such a correction for $\mathrm{SF}_{6}$ derived AoA (Hall and Plumb, 1994).

Ravishankara et al. (1993) reported the atmospheric lifetime of $\mathrm{SF}_{6}$ to be 3200 years by considering electron attachment and vacuum ultraviolet (VUV) photolysis. They also studied the loss of $\mathrm{SF}_{6}$ by reaction with $\mathrm{O}\left({ }^{1} \mathrm{D}\right)$ but found the rate too slow to be important. They deduced that electron attachment was the dominant loss process and quantified this process using a 2-D model, wherein they assumed that all $\mathrm{SF}_{6}$ molecules are destroyed after attachment of an electron (with a rate constant of $10^{-9} \mathrm{~cm}^{3}$ molecule ${ }^{-1} \mathrm{~s}^{-1}$ ). They therefore argued that their lifetime of 3200 years could be a lower limit, but clearly this result depends on the accuracy of the 2-D electron density, which was calculated using only photochemistry. Morris et al. (1995) subsequently extended the work of Ravishankara et al. (1993) by including an ion chemistry module in the same 2-D model. They also made other assumptions to maximize the impact of electron attachment on $\mathrm{SF}_{6}$ loss and derived a lifetime as short as 800 years (which could be further sporadically decreased by large solar proton events). Using a 3-D middle atmosphere model, Reddmann et al. (2001) estimated the lifetime to be 472 years when $\mathrm{SF}_{6}$ is irreversibly destroyed purely by direct electron attachment and to be 9379 years when $\mathrm{SF}_{6}$ loss is assumed to occur only via indirect loss (via the formation of $\mathrm{SF}_{6}^{-}$) and ionization via the reactions with $\mathrm{O}_{2}^{+}$and $\mathrm{N}_{2}^{+}$. They concluded that the estimated lifetime depends strongly on the electron attachment mechanism because the efficiency of this process as a permanent removal process of $\mathrm{SF}_{6}$ depends on the competition between the reaction of $\mathrm{SF}_{6}^{-}$with $\mathrm{H}$ and $\mathrm{HCl}$ and the photodetachment and reaction with $\mathrm{O}$ and $\mathrm{O}_{3}$. Here we extend the above studies and investigate the $\mathrm{SF}_{6}$ lifetime using a state-of-the-art 3-D chemistry climate model with a domain from the surface to $140 \mathrm{~km}$. Our modelled electron density is based on results of a detailed ion chemistry model, and we use a detailed methodology for treating the atmospheric background electrons, which is based on Troe's formalism (Troe et al., 2007a, b; Viggiano et al., 2007).

In addition to determining the $\mathrm{SF}_{6}$ lifetime, in this study we report new measurements of the infrared absorption cross sections for $\mathrm{SF}_{6}$ and input these into a line-by-line radiative transfer model in order to obtain radiative forcings and efficiencies. These values are then used to determine more accurate values of global warming potentials (GWPs) based on their cloudy-sky adjusted radiative efficiencies. GWP is the metric used by the World Meteorological Organisation (WMO) and Intergovernmental Panel on Climate Change (IPCC) to compare the potency of a greenhouse gas relative to an equivalent emission of $\mathrm{CO}_{2}$ over a set time period. The definitions of these radiative terms are given in Appendix A.

\section{Methodology}

\subsection{WACCM 3-D model}

To simulate atmospheric $\mathrm{SF}_{6}$ we have used the Whole Atmosphere Community Climate Model (WACCM). Here we use WACCM 4 (Marsh et al., 2013), which is part of the NCAR Community Earth System Model (CESM; Lamarque et al., 
Table 1. $\mathrm{SF}_{6}$ loss reactions included in WACCM.

\begin{tabular}{|c|c|c|}
\hline Loss process & Rate constant & Reference and comments \\
\hline $\mathrm{Na}+\mathrm{SF}_{6}$ & $k=1.80 \times 10^{-11} \exp (-590.5 / T)$ & $\begin{array}{l}\text { From Totterdill et al. (2015); refitted for } \\
\text { mesospheric temperatures } 215-300 \mathrm{~K} \text {. }\end{array}$ \\
\hline $\mathrm{K}+\mathrm{SF}_{6}$ & $k=13.4 \times 10^{-11} \exp (-860.6 / T)$ & $\begin{array}{l}\text { From Totterdill et al. (2015); refitted for } \\
\text { mesospheric temperatures } 215-300 \mathrm{~K} \text {. }\end{array}$ \\
\hline \multirow{6}{*}{$\begin{array}{l}\text { Electron } \\
\text { attachment }\end{array}$} & Associative attachment: & \multirow[t]{6}{*}{ Totterdill et al. (2015). } \\
\hline & $k_{\mathrm{EA}, \text { ass }}=k_{\mathrm{at}} \times\left(k_{(\mathrm{SF} 6-+\mathrm{H})}[\mathrm{H}]+\right.$ & \\
\hline & $\left.\left.k_{(\mathrm{SF} 6-}+\mathrm{HCl}\right)[\mathrm{HCl}]\right) /\left(j_{\mathrm{PD}}+k_{(\mathrm{SF} 6-}+\mathrm{H}\right)[\mathrm{H}]+$ & \\
\hline & $\left.k_{(\mathrm{SF} 6-+\mathrm{HCl})}[\mathrm{HCl}]+k_{(\mathrm{SF} 6-}+\mathrm{O}_{3}\left[\mathrm{O}_{3}\right]+k_{(\mathrm{SF} 6-+\mathrm{O})}[\mathrm{O}]\right)$ & \\
\hline & Dissociative attachment: & \\
\hline & $\begin{array}{l}k_{\mathrm{EA}, \mathrm{diss}}=k_{\mathrm{at}} \times \beta, \\
\text { where } \beta \text { is the fraction of } \mathrm{SF}_{6}^{-} \text {that dissociates into } \mathrm{SF}_{5}^{-} \text {. }\end{array}$ & \\
\hline \multirow[t]{2}{*}{ Photolysis } & Lyman $\alpha: \sigma(121.6 \mathrm{~nm})=1.37 \times 10^{-18} \mathrm{~cm}^{2}$ & \multirow[t]{2}{*}{ Totterdill et al. (2015). } \\
\hline & $\begin{array}{l}\text { Parameterized expression over the range of } 115-180 \mathrm{~nm} \text {, } \\
\text { based on previous measurements. }\end{array}$ & \\
\hline
\end{tabular}

2012), configured to have 88 pressure levels from the surface to the lower thermosphere $\left(5.96 \times 10^{-6} \mathrm{~Pa}, 140 \mathrm{~km}\right)$ and a horizontal resolution of $1.9^{\circ} \times 2.5^{\circ}$ (latitude $\times$ longitude) . The model contains a detailed treatment of middle atmosphere chemistry including interactive treatments of $\mathrm{Na}$ and $\mathrm{K}$ (Plane et al., 2015). We use the specified dynamics (SD) version of the model to allow comparison with observations (see Garcia et al., 2014, for details). The $\mathrm{SF}_{6}$ surface emission flux and initial global vertical profiles were taken from a CCMI (Chemistry Climate Model Initiative) simulation using the same version of SD-WACCM with the same nudging analyses (D. Kinnison, personal communication, 2013).

Lyman- $\alpha$ photolysis is the only $\mathrm{SF}_{6}$ loss reaction in the standard version of WACCM, and in this work we have added the additional processes given in Table 1. The rate constants for the $\mathrm{SF}_{6}+$ metal reactions have been measured in our laboratory for mesospheric conditions (Totterdill et al., 2015); here we use the experimental values for the reactions with $\mathrm{Na}$ and $\mathrm{K}$. For the photolysis of $\mathrm{SF}_{6}$ we used the standard WACCM methodology but with the updated Lyman- $\alpha$ cross section from our laboratory of $1.37 \times 10^{-18} \mathrm{~cm}^{2}$ molecule ${ }^{-1}$ (Totterdill et al., 2015). The WACCM Lyman- $\alpha$ flux is taken from Chabrillat and Kockarts (1997).

Electron attachment to $\mathrm{SF}_{6}$ plays a major role in its atmospheric removal and so both dissociative and nondissociative attachment are considered in this study. The detailed method is described in a recent paper (Totterdill et al., 2015) and here only a brief summary is given. The removal process by the attachment of low-energy electrons to $\mathrm{SF}_{6}$ can be described using Troe's theory (Troe et al., 2007a, b; Viggiano et al., 2007). In the middle and lower mesosphere, electrons are mostly attached to neutral species in the form of anions. However, above $80 \mathrm{~km}$ the concentration of free electrons increases and the direct electron attachment to $\mathrm{SF}_{6}$ becomes more likely. This can happen either by associative attachment forming the $\mathrm{SF}_{6}^{-}$anion, which can then undergo chemical reactions with $\mathrm{H}, \mathrm{O}, \mathrm{O}_{3}$ and $\mathrm{HCl}$, or by dissociative attachment forming the $\mathrm{SF}_{5}^{-}$anion fragment. The probability $\beta$ of dissociative attachment when an electron is captured by $\mathrm{SF}_{6}$ is given by

$\beta(p, T)=\frac{k_{\mathrm{dis}}}{k_{\mathrm{at}}+k_{\mathrm{dis}}}$,

where $k_{\text {dis }}$ is the rate constant for dissociative attachment and $k_{\text {at }}$ is the rate constant for associative attachment. $\beta$ can be expressed as

$$
\begin{aligned}
\beta(p, T) & =\exp (-4587 T+7.74) \\
& \times 10^{\left[4.362-0.582 \log _{10}(p / \text { Torr })-0.0203\left(\log _{10}\left(\frac{p}{\text { Torr }}\right)\right)^{2} / 5.26 \times 10^{-4}\right]},
\end{aligned}
$$

where $T$ is the temperature in $\mathrm{K}$ and $p$ is the pressure in Torr (Totterdill et al., 2015).

We include both associative and dissociative electron attachment using WACCM-predicted electron concentrations (see Table 1). Note that the $\mathrm{SF}_{6}^{-}$anion is not modelled directly. As it is short-lived, we can treat it as being in steady state and consider the relative rates of its destruction pathways. Therefore, the net $\mathrm{SF}_{6}$ attachment loss rate is calculated by multiplying $k_{\mathrm{at}}$ by the ratio of permanent destruction of the resulting $\mathrm{SF}_{6}^{-}$(reactions of $\mathrm{SF}_{6}^{-}$with $\mathrm{H}$ and $\mathrm{HCl}$ ) to the total sum of these reactions plus processes which recycle $\mathrm{SF}_{6}^{-}$to $\mathrm{SF}_{6}$ (reactions with $\mathrm{O}$ and $\mathrm{O}_{3}$, and photodetachment). The $\mathrm{SF}_{6}^{-}$photodetachment rate of $0.11 \mathrm{~s}^{-1}$ at midday was estimated using photodetachment cross sections from Eisfeld (2011; 280-376 nm) and Bopp et al. (2007; 376$707 \mathrm{~nm}$ ). Note there is a typographical error in Totterdill et al. (2015) where the rate is stated as $1.1 \mathrm{~s}^{-1}$.

In order to use a realistic electron concentration, the role of negative ions in the $D$ region must be considered. The $D$ region is the lowest part of the ionosphere, extending from about 60 to $85 \mathrm{~km}$. It is characterized by the appearance of cluster ions (e.g. proton hydrates $\mathrm{H}^{+} \cdot\left(\mathrm{H}_{2} \mathrm{O}\right)_{n}$, where 
Table 2. Positive and negative ions included in WACCM-SIC.

\begin{tabular}{ll}
\hline Positive ions & $\mathrm{O}_{2}^{+}, \mathrm{O}_{4}^{+}, \mathrm{NO}^{+}, \mathrm{NO}^{+}\left(\mathrm{H}_{2} \mathrm{O}\right)$, \\
& $\mathrm{O}_{2}^{+}\left(\mathrm{H}_{2} \mathrm{O}\right), \mathrm{H}^{+}\left(\mathrm{H}_{2} \mathrm{O}\right), \mathrm{H}^{+}\left(\mathrm{H}_{2} \mathrm{O}\right)_{2}$, \\
& $\mathrm{H}^{+}\left(\mathrm{H}_{2} \mathrm{O}\right)_{3}, \mathrm{H}^{+}\left(\mathrm{H}_{2} \mathrm{O}\right)_{4}, \mathrm{H}^{+}\left(\mathrm{H}_{2} \mathrm{O}\right)_{5}$, \\
& $\mathrm{H}^{+}\left(\mathrm{H}_{2} \mathrm{O}\right)_{6}, \mathrm{H}_{3} \mathrm{O}^{+}\left(\mathrm{H}_{2} \mathrm{O}\right)_{2}\left(\mathrm{CO}_{2}\right)$, \\
& $\mathrm{H}_{3} \mathrm{O}^{+}(\mathrm{OH}), \mathrm{O}_{2}^{+}\left(\mathrm{CO}_{2}\right)$, \\
& $\mathrm{H}_{3} \mathrm{O}^{+}(\mathrm{OH})\left(\mathrm{CO}_{2}\right), \quad \mathrm{H}_{3} \mathrm{O}^{+}(\mathrm{OH})\left(\mathrm{H}_{2} \mathrm{O}\right)$, \\
& $\mathrm{O}_{2}^{+}\left(\mathrm{H}_{2} \mathrm{O}\right)\left(\mathrm{CO}_{2}\right), \mathrm{O}_{2}^{+}\left(\mathrm{H}_{2} \mathrm{O}\right)_{2}, \mathrm{O}_{2}^{+}\left(\mathrm{N}_{2}\right)$, \\
& $\mathrm{NO}^{+}\left(\mathrm{H}_{2} \mathrm{O}\right)_{2}, \mathrm{H}^{+}\left(\mathrm{H}_{2} \mathrm{O}\right)\left(\mathrm{CO}_{2}\right)$, \\
& $\mathrm{O}^{+}, \mathrm{N}^{+}, \mathrm{N}_{2}^{+}, \mathrm{NO}^{+}\left(\mathrm{H}_{2} \mathrm{O}\right)_{3}, \mathrm{O}_{4}^{+}$, \\
& $\mathrm{H}^{+}\left(\mathrm{H}_{2} \mathrm{O}\right)_{2}\left(\mathrm{CO}_{2}\right), \mathrm{H}^{+}\left(\mathrm{H}_{2} \mathrm{O}\right)_{2}\left(\mathrm{~N}_{2}\right)$ \\
\hline Negative ions & $\mathrm{O}_{3}^{-}, \mathrm{O}^{-}, \mathrm{O}_{2}^{-}, \mathrm{OH}^{-}, \mathrm{O}_{2}^{-}\left(\mathrm{H}_{2} \mathrm{O}\right)$, \\
& $\mathrm{O}_{2}^{-}\left(\mathrm{H}_{2} \mathrm{O}\right)_{2}, \mathrm{O}_{4}^{-}, \mathrm{CO}_{3}^{-}, \mathrm{CO}_{3}^{-}\left(\mathrm{H}_{2} \mathrm{O}\right)$, \\
& $\mathrm{CO}_{4}^{-}, \mathrm{HCO}_{3}^{-}, \mathrm{NO}_{2}^{-}, \mathrm{NO}_{3}^{-}, \mathrm{NO}_{3}^{-}\left(\mathrm{H}_{2} \mathrm{O}\right)$, \\
& $\mathrm{NO}_{3}^{-}\left(\mathrm{H}_{2} \mathrm{O}\right)_{2}, \mathrm{NO}_{3}^{-}\left(\mathrm{HNO}_{3}\right)$, \\
& $\mathrm{NO}_{3}^{-}\left(\mathrm{HNO}_{3}\right)_{2}, \mathrm{Cl}^{-}, \mathrm{ClO}^{-}, \mathrm{NO}_{2}^{-}\left(\mathrm{H}_{2} \mathrm{O}\right)$, \\
& $\mathrm{Cl}^{-}\left(\mathrm{H}_{2} \mathrm{O}\right), \mathrm{Cl}^{-}\left(\mathrm{CO}_{2}\right), \mathrm{Cl}^{-}\left(\mathrm{HCl}^{2}\right)$ \\
\hline
\end{tabular}

$n \leq 6)$ and negative ions (e.g. $\mathrm{O}_{2}^{-}, \mathrm{CO}_{3}^{-}$and $\mathrm{NO}_{3}^{-}$) rather than free electrons. These species predominate because the atmospheric pressure is high enough to facilitate the threebody attachment of ligand species like $\mathrm{H}_{2} \mathrm{O}$ to positive ions and electrons to neutral molecules. Therefore, a scaling factor was introduced that converts the standard WACCM electron concentrations, which are calculated from charge balance with the five major positive $E$ region ions $\left(\mathrm{N}^{+}, \mathrm{N}_{2}^{+}\right.$, $\mathrm{O}^{+}, \mathrm{O}_{2}^{+}$and $\mathrm{NO}^{+}$), to more realistic electron concentrations. We have recently incorporated the Sodankylä Ion Chemistry (SIC) model into the standard version of WACCM to produce a new version (WACCM-SIC) containing a detailed $D$ region ion chemistry with cluster ions and negative ions (Kovács et al., 2016). The mesospheric positive and negative ions in WACCM-SIC are listed in Table 2. The electron scaling factor in each grid box of WACCM was then defined as the annually averaged ratio of $[e]_{\text {WACCM-SIC }} /[e]_{\text {WACCM }}$ for the year 2013 , where $[e]_{\text {WACCM-SIC }}$ is the electron density calculated from WACCM-SIC and $[e]_{\text {WACCM }}$ from the standard WACCM.

The scaling factor, which varies with altitude and latitude, is shown in Fig. 1 (bottom panel) together with the electron densities from the standard WACCM (top panel) and WACCM-SIC (middle panel) models. The annually averaged electron concentration in the WACCM-SIC model is significantly smaller in the lower and middle mesosphere than in the standard WACCM, which is expected because of negative ion formation. In the polar regions the scaling factor is around 0.01 at $50 \mathrm{~km}$ and 0.5 at $70 \mathrm{~km}$. Note that in the upper mesosphere $(70-80 \mathrm{~km})$, the electron density in WACCM-SIC is larger than WACCM, by over a factor of 5 near the poles. This results from the inclusion of mediumenergy electrons (MEE) (electrons with an energy between $30 \mathrm{keV}$ and $2 \mathrm{MeV}$ ) in WACCM-SIC. Figure 2 shows the
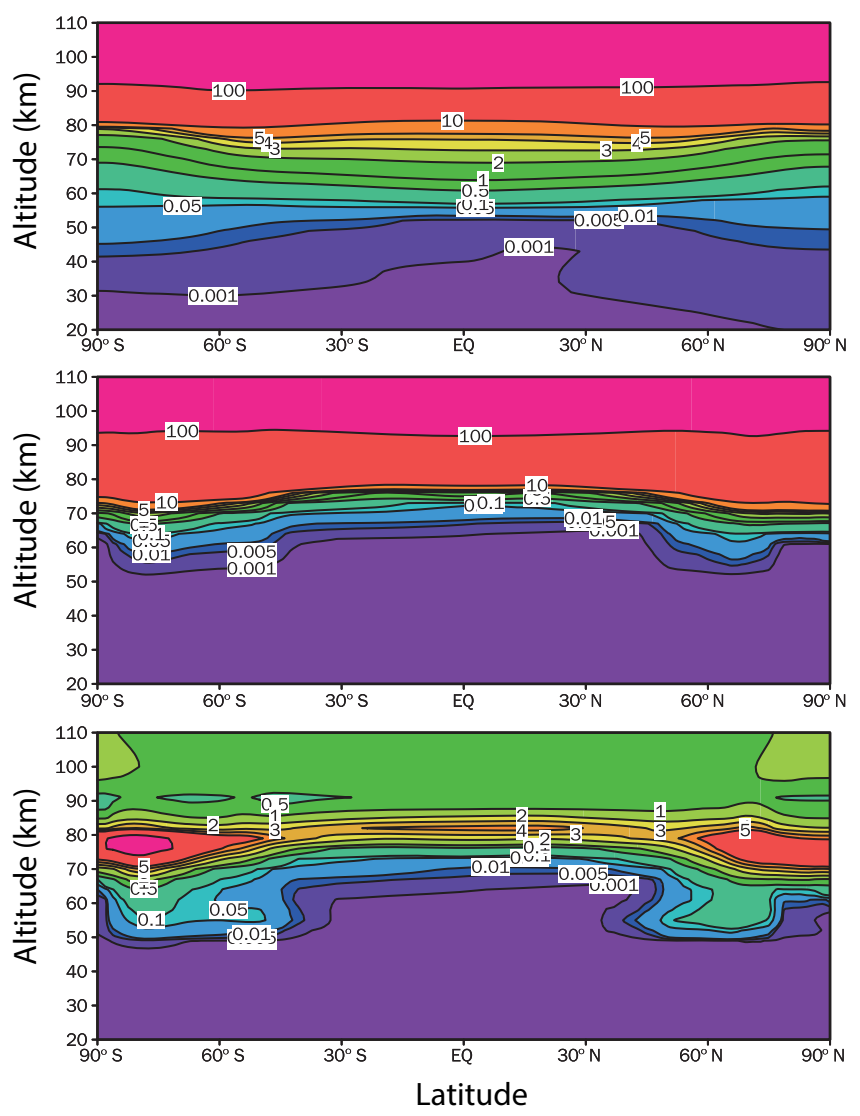

Figure 1. Top: annual average electron concentration for 2013 from the standard WACCM model (in $10^{2}$ electrons $\mathrm{cm}^{-3}$ ). Middle: annual average electron concentration for 2013 from WACCM-SIC model (in $10^{2}$ electrons $\mathrm{cm}^{-3}$ ). Bottom: annually averaged electron scaling factor for 2013 .

effect of MEE by comparing WACCM-SIC runs with and without this source of ionization in the upper mesosphere included. To describe the effect of ionization, WACCM-SIC uses ionization rates $(I)$ as a function of time and pressure, which were calculated from the spectra based on the proton energy-range measurements in standard air as described by Verronen et al. (2005). According to Fig. 3 of Meredith et al. (2015), the annually averaged medium-energy electron flux for 2013 approximately corresponds to the long-term, 20 -year average. This allows us to assume that the annually averaged electron density of 2013 from WACCM-SIC can be used to scale the long-term simulations using the standard WACCM aimed at determining the atmospheric lifetime of $\mathrm{SF}_{6}$.

The WACCM simulation included five different $\mathrm{SF}_{6}$ tracers in order to quantify the importance of different loss processes. All of these tracers used the same emissions but differed in their treatment of $\mathrm{SF}_{6}$ loss reactions. One $\mathrm{SF}_{6}$ tracer included no atmospheric loss (i.e. a passive tracer). Three tracers included one of the following loss processes for $\mathrm{SF}_{6}$ : (i) reaction with mesospheric metals $(\mathrm{Na}, \mathrm{K})$, (ii) electron 

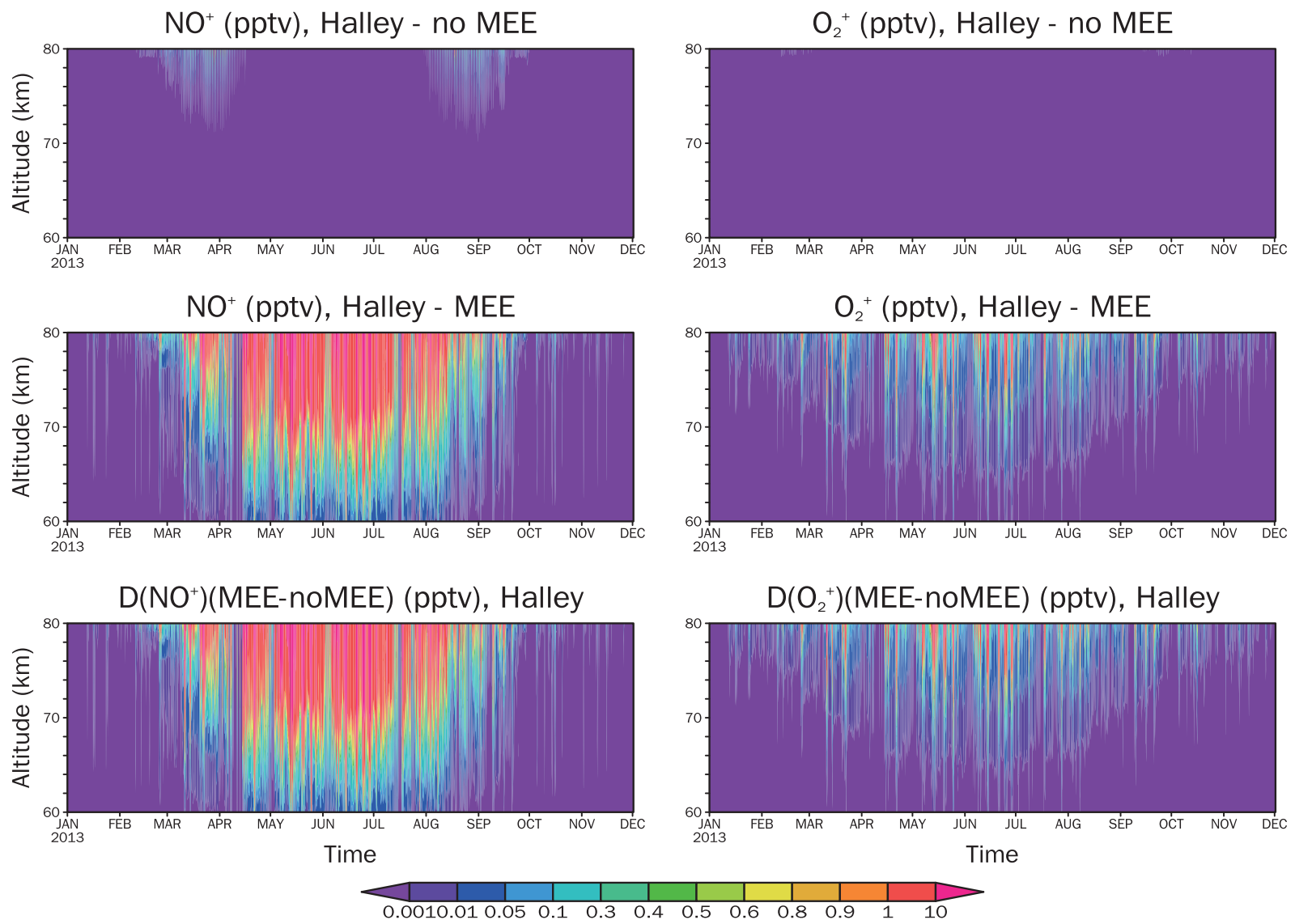

Figure 2. Time series of volume mixing ratio profiles (pptv) of $\mathrm{NO}^{+}$(left panels) and $\mathrm{O}_{2}^{+}$(right panels) above $\mathrm{Halley}\left(76^{\circ} \mathrm{S}\right)$ from two WACCM-SIC simulations. Top panels show the values obtained from the model run without medium-energy electrons (MEE); the middle panels show the run with medium-energy electrons; and the bottom panels show the absolute differences between the two model runs.

attachment and (iii) UV photolysis. Finally, one "total reactive" $\mathrm{SF}_{6}$ tracer included all three loss processes. This total reactive tracer should be the most realistic and was used in the radiative forcing calculations. WACCM was run for the period 1990-2007, and the first 5 years were treated as spinup. For the analysis the monthly mean model outputs were saved and later globally averaged for the lifetime calculations.

\subsection{Infrared absorption spectrum and radiative forcing}

Previous quantitative infrared absorption spectra of $\mathrm{SF}_{6}$ have been compared in Hodnebrog et al. (2013; their Table 12). There are differences of $\sim 10 \%$ between existing integrated cross section estimates, and the measurements cover different spectral ranges. We therefore performed a more complete set of measurements over a wider spectral range, in order to reduce uncertainty in the absorption spectrum and hence the radiative efficiency of $\mathrm{SF}_{6}$. Measurements were taken using an experimental configuration consisting of a Bruker Fourier transform spectrometer (Model IFS/66), which was fitted with a mid-infrared (MIR) source used to generate radiation which passed through an evacuable gas cell with optical path length $15.9 \mathrm{~cm}$. The cell was fitted with $\mathrm{KBr}$ windows, which allow excellent transmission between 400 and $40000 \mathrm{~cm}^{-1}$. The choice of source and window were selected so as to admit radiation across the mid-IR range where bands of interest are known to occur. Room temperature $(296 \pm 2 \mathrm{~K})$ measurements were carried out between 400 and $2000 \mathrm{~cm}^{-1}$ at a spectral resolution of $0.1 \mathrm{~cm}^{-1}$ and compiled from the averaged total of 128 scans to 32 background scans at a scanner velocity of $1.6 \mathrm{kHz}$. Gas mixtures were made using between 8 and 675 Torr of $\mathrm{SF}_{6}$ diluted up to an atmosphere using $\mathrm{N}_{2}$, according to the method described in Totterdill et al. (2016).

Radiative forcing calculations were made using the Reference Forward Model (RFM; Dudhia, 2013), which is a line-by-line radiative transfer model based on the previous GENLN2 model (Edwards, 1987). Results obtained from this model were validated against the DISORT radiative transfer solver (Stamnes et al., 2000) included within the libRadtran (Library for Radiative Transfer) package (Mayer and Kylling, 2005). A full description of these models and parameters used alongside discussion of the treatment of clouds and model comparison is also given in Totterdill et al. (2016). 


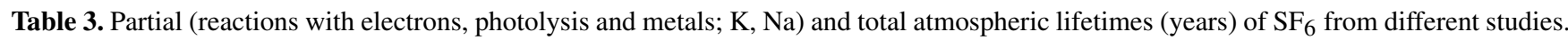
Numbers in parentheses show relative percentage contributions of loss due to the different processes.

\begin{tabular}{lllll}
\hline \multirow{2}{*}{ Study } & \multicolumn{3}{c}{ Lifetime/years } & \\
\cline { 2 - 4 } & Photolysis & Electron attachment & Total & Model dimensions \\
\hline Ravishankara et al. (1993) & $13000(24 \%)$ & $4210(76 \%)$ & 3200 & 2-D \\
Morris et al. (1995) & N/A & N/A & 800 & $2-\mathrm{D}$ \\
This work & $48000(2.6 \%)$ & $1339(97.4 \%)$ & 1278 & $3-\mathrm{D}$ \\
\hline
\end{tabular}

\section{Results}

\subsection{Global distributions of SF6 from WACCM simulations}

Figure 3 shows typical zonal mean profiles of the WACCM $\mathrm{SF}_{6}$ tracers in the north and south polar regions for different seasons, compared to MIPAS (Michelson Interferometer for Passive Atmospheric Sounding) observations for the year 2007 (Haenel et al., 2015). Although the MIPAS SF 6 data provide much more coverage horizontally and vertically compared to in situ aircraft and balloon data, they have only been validated up to $35 \mathrm{~km}$ (Stiller et al., 2008). Validation at higher altitudes is not possible due to the lack of suitable reference data. Details of the validation of the MIPAS data version used here (V5h_SF6_20 for the full-resolution product from 2004 and earlier; V5r_SF6_222 and V5r_SF6_223 for the reduced-resolution period of 2005 and later) can be found in Haenel et al. (2015), including Fig. S2 of their Supplement. The WACCM passive $\mathrm{SF}_{6}$ tracer has a mixing ratio profile that is almost constant with altitude in the stratosphere and lower mesosphere below $60 \mathrm{~km}$ and then decreases by about $10 \%$ by $70 \mathrm{~km}$, after which it decreases more rapidly. Comparison of the tracers that include loss processes show that the removal of $\mathrm{SF}_{6}$ is dominated by electron attachment, with a small contribution $(<3 \%)$ directly from photolysis. The mesospheric metals make a negligible contribution because the $\mathrm{Na}$ and $\mathrm{K}$ layers occur in the upper mesosphere above $80 \mathrm{~km}$ (with peaks around $90 \mathrm{~km}$ ), and the concentrations of these metal atoms are too low. Figure 3 shows that the model mean profile agrees well with the MIPAS mean in the polar lower stratosphere (around $20 \mathrm{~km}$ ) but exhibits a positive bias of around $1 \mathrm{pptv}$ at higher altitudes in the middle stratosphere. However, the figure also shows that the variability in the observed $\mathrm{SF}_{6}$ at high latitudes is large. The time variation of modelled $\mathrm{SF}_{6}$ shown in Fig. 4 corre-


a $0.29 \mathrm{pptv} \mathrm{yr}^{-1}$ increase in global mean volume mixing ratio, and a volume mixing ratio of $6.4 \mathrm{pptv}$ by the end of 2007 .

Figure 5 shows the zonal mean annual mean $\mathrm{SF}_{6}$ distribution from the five WACCM tracers and MIPAS observations for 2007. Figure 5a (and Fig. 3) shows that there is a rapid decrease in $\mathrm{SF}_{6}$ above $75 \mathrm{~km}$ even for the inert tracer. This can be explained by diffusive separation, which becomes pro- nounced in the upper mesosphere because $\mathrm{SF}_{6}$ is a relatively heavy molecule (molar mass $0.146 \mathrm{~kg}$ ) compared to the mean mass of air molecules (mean molar mass $0.0288 \mathrm{~kg}$; cf. Garcia et al. 2014, where similar behaviour is seen for $\mathrm{CO}_{2}$, another relatively heavy molecule). Panels a-c of the figure all show $\mathrm{SF}_{6}$ decreasing above $\sim 80 \mathrm{~km}$, and panels a and $\mathrm{c}$ are almost identical, while in panel $\mathrm{b}$ the decrease begins about $4 \mathrm{~km}$ lower. This is all consistent with the notion that metals do not affect $\mathrm{SF}_{6}$ and photolysis contributes only slightly. The fact that diffusive separation prevents $\mathrm{SF}_{6}$ from reaching altitudes where photolysis is faster must be contributing to the very long lifetime (48000 years, Table 3 ) found when photolysis is the only loss considered. By contrast, in Fig. 5d $\mathrm{SF}_{6}$ decreases rapidly above $70 \mathrm{~km}$, which is related to the fact that loss via electron attachment is important at these lower altitudes. Thus, in this case, $\mathrm{SF}_{6}$ loss occurs below the altitudes $(\sim 90 \mathrm{~km})$ where diffusive separation is important (and where air density is higher), which makes it a much more effective loss mechanism. The WACCM SF 6 tracer that includes all loss processes (Fig. 5e) has a very similar distribution to that which only treats loss due to electron attachment (Fig. 5d), which emphasizes how this process dominates $\mathrm{SF}_{6}$ loss in the model. This model tracer can be compared to the MIPAS observations in Fig. 5f, which shows that WACCM appears to reproduce the general features of the MIPAS distribution (note the smaller altitude range in panels e and $f$ of Fig. 5). However, it is also clear that WACCM SF 6 , even with all losses considered, decreases with altitude much more slowly at all latitudes than MIPAS SF 6 . This could indicate a problem with the model's meridional transport. However, a BDC that is too fast would tend to produce low levels of $\mathrm{SF}_{6}$ at middle and high latitudes in the descending branch, which does not seem to be the case. Therefore, at least two other possible scenarios could be responsible for the discrepancy: $\mathrm{SF}_{6}$ loss in WACCM is still somewhat underestimated despite the inclusion of the electron attachment, or MIPAS $\mathrm{SF}_{6}$ is biased low above $\sim 20 \mathrm{~km}$.

\subsection{Atmospheric lifetime}

The atmospheric lifetime is defined as the ratio of the atmospheric burden to the atmospheric loss rate. This definition was used to calculate annual mean lifetime values from the WACCM output containing the individual rates for the 

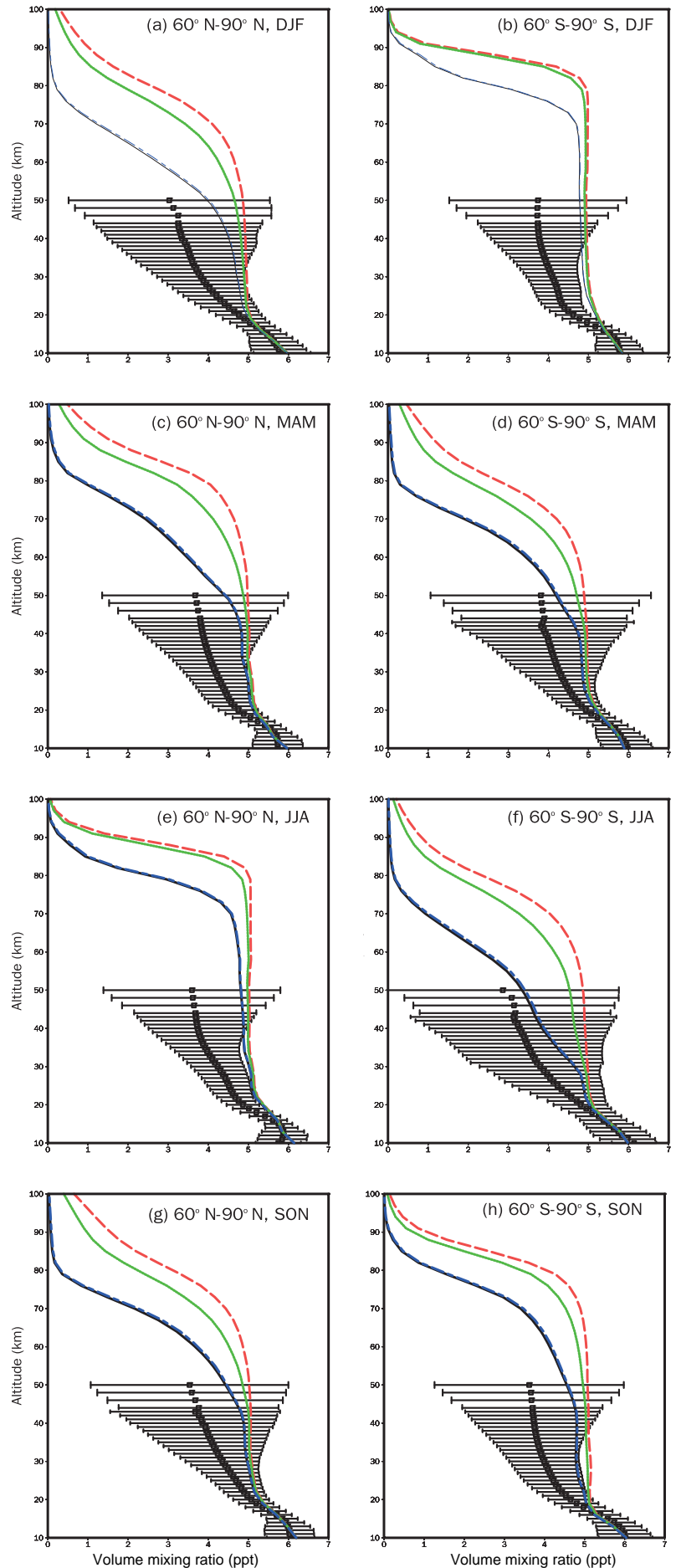

Figure 3. Seasonal mean volume mixing ratios (pptv) of the different $\mathrm{SF}_{6}$ tracers for the polar regions $\left(60-90^{\circ} \mathrm{N}\right.$ and $60-90^{\circ} \mathrm{S}$ latitudes) in 2007 as a function of altitude for MIPAS (Michelson Interferometer for Passive Atmospheric Sounding) satellite-observed $\mathrm{SF}_{6}$ (black symbols with standard deviations for $\pm 1 \sigma$; Stiller et al., 2012), the total WACCM-SF 6 (blue solid line), the photolysis WACCM-SF 6 tracer (green solid line) and the inert WACCM SF 6 tracer (red dashed line).

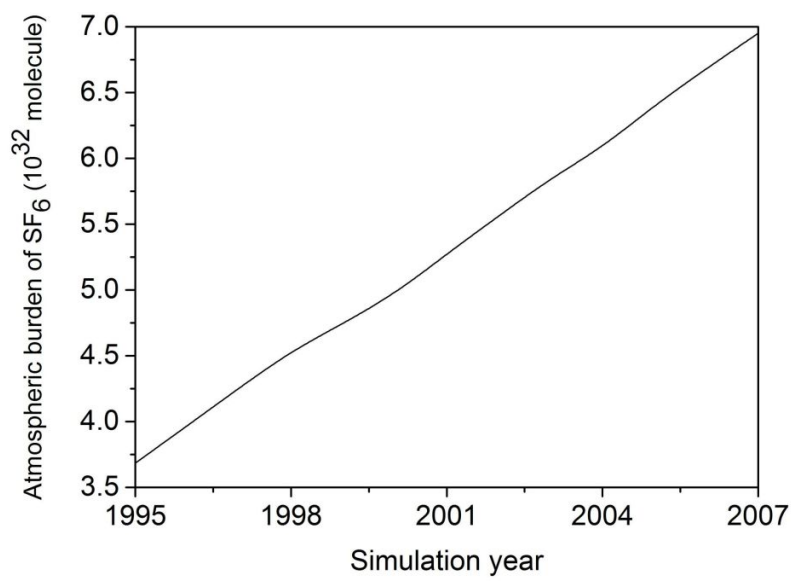

Figure 4. Variation of the total annual atmospheric burden of $\mathrm{SF}_{6}$ during the simulation from 1995 to 2007 . According to this the emission rate (slope) was determined to be $6.5 \times 10^{-3} \mathrm{Tg} \mathrm{yr}^{-1}$



different loss processes. During the simulation the total atmospheric burden of $\mathrm{SF}_{6}$ increased linearly as expected (see Fig. 4) from $3.4 \times 10^{32}$ molecules with an annual increment of $2.3 \times 10^{31}$ molecules $\mathrm{yr}^{-1}$. Figure 6 shows the variation in $\mathrm{SF}_{6}$ lifetime from 1995 to 2007 , corresponding to a full solar cycle (the solar minima occurred in May 1996 and January 2008). The figure demonstrates that the lifetime has a strong dependence on solar activity, being anti-correlated with solar activity, for example as measured by the radio flux at $10.7 \mathrm{~cm}(2800 \mathrm{MHz}$; Tapping, 2013), which ranges over $(72-183) \times 10^{-22} \mathrm{~W} \mathrm{~m}^{-2} \mathrm{~Hz}^{-1}$, with an average value of $90.3 \times 10^{-22} \mathrm{~W} \mathrm{~m}^{-2} \mathrm{~Hz}^{-1}$. The mean $\mathrm{SF}_{6}$ lifetime over the same solar cycle period is 1278 years, with a range from 1120 to 1475 years. The annual averaged electron number density in the polar regions is also plotted in Fig. 6; as expected, it is correlated with the $10.7 \mathrm{~cm}$ radio emission (Tapping, 2013).

As noted in Sect. 1, the $\mathrm{SF}_{6}$ lifetime has been reported to be 3200 years by Ravishankara et al. (1993). For this they used a total electron attachment rate constant of $k_{\mathrm{EA}}=10^{-9} \mathrm{~cm}^{3} \mathrm{~s}^{-1}$. In Morris et al. (1995) the calculated lifetime decreased to 800 years by considering ion chemistry and assuming that the associative attachment forming $\mathrm{SF}_{6}^{-}$ does not regenerate the parent molecule, thereby obtaining a lower limit for the lifetime. Reddmann et al. (2001) estimated the lifetime to be 472 years when $\mathrm{SF}_{6}$ is irreversibly destroyed purely by direct electron attachment and to be 9379 years when $\mathrm{SF}_{6}$ loss is assumed to occur only via indirect loss (via the formation of $\mathrm{SF}_{6}^{-}$) and ionization via the reactions with $\mathrm{O}_{2}^{+}$and $\mathrm{N}_{2}^{+}$. In the present study we have directly applied Troe's theory (Troe et al., 2007a, b; Viggiano et al., 2007) to determine the efficiency of electron attachment as a function of temperature and pressure and the branching 
(a) $\mathrm{SF}_{6}$ inert tracer, ppt

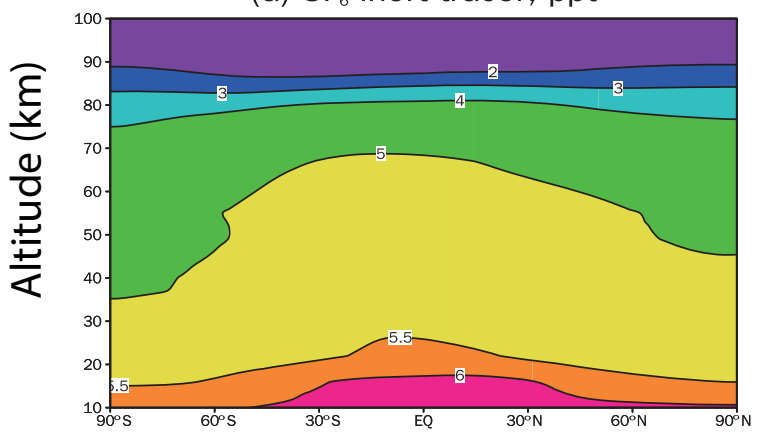

(c) $\mathrm{SF}_{6}$ metal loss tracer, ppt



(e) $\mathrm{SF}_{6}$ ppt - WACCM

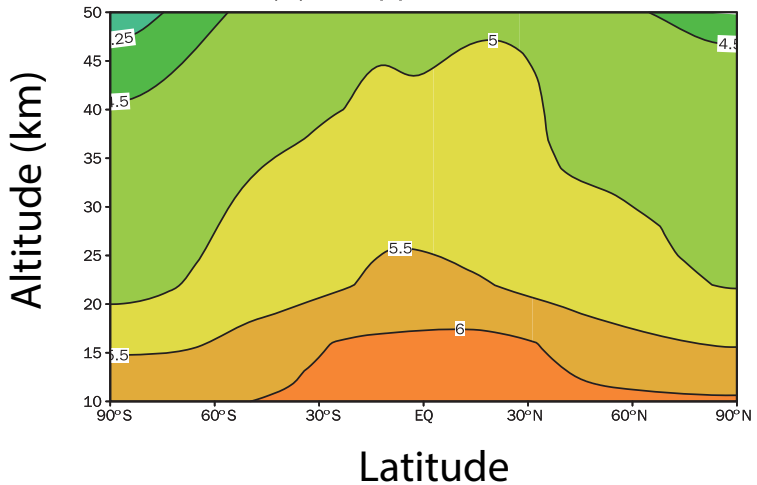

(b) $\mathrm{SF}_{6}$ photolysis tracer, ppt



(d) $\mathrm{SF}_{6}$ electron loss tracer, ppt

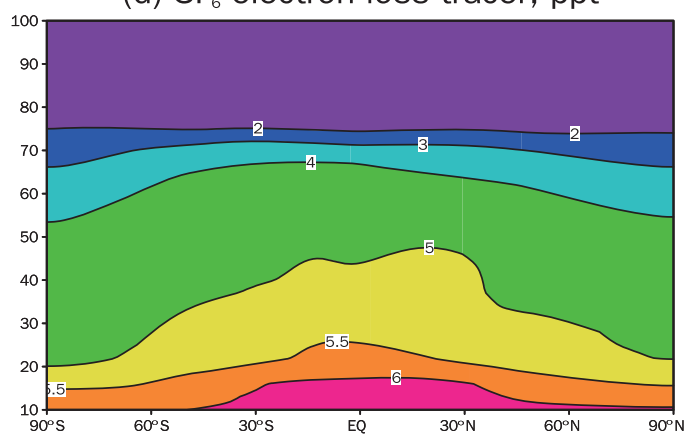

(f) $\mathrm{SF}_{6}$ ppt - MIPAS

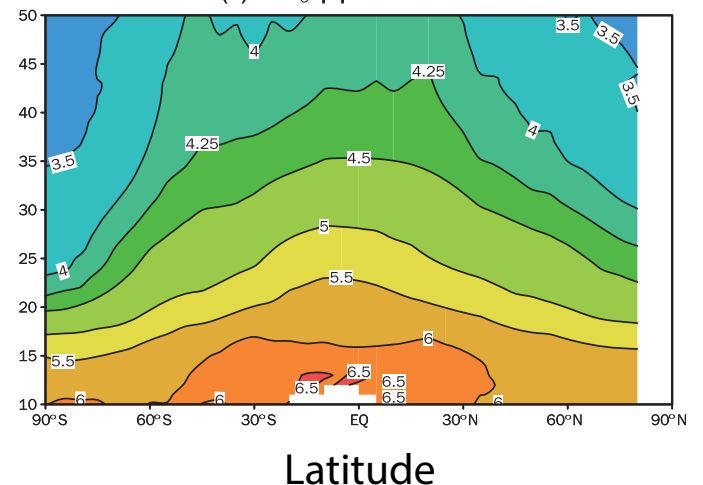

Figure 5. Annual zonal mean latitude-height volume mixing ratios (pptv) of the different $\mathrm{WACCM}_{\mathrm{SF}}$ tracers in 2007: (a) inert $\mathrm{SF}_{6}$ tracer; (b) $\mathrm{SF}_{6}$ tracer removed by photolysis only; (c) $\mathrm{SF}_{6}$ tracer removed by mesospheric metals only; (d) $\mathrm{SF}_{6}$ tracer removed by electron attachment only; and (e) total reactive $\mathrm{SF}_{6}$. Panel (f) shows the $\mathrm{SF}_{6}$ volume mixing ratio for 2007 from MIPAS observations. Note the different altitude ranges and contour intervals for panels (a)-(d) versus panels (e)-(f).

ratio for dissociative attachment (Eq. 2), which we extrapolated to mesospheric conditions (Totterdill et al., 2015).

Our estimated partial lifetime of $\mathrm{SF}_{6}$ due to photolysis (i.e. the lifetime calculated considering photolysis as the only atmospheric loss process) for the $\mathrm{SF}_{6}$ tracer which includes all loss processes is 48000 years, which is considerably longer than that the 13000 years determined by Ravishankara et al. (1993) despite our Lyman$\alpha$ cross section $\left(1.37 \times 10^{-18} \mathrm{~cm}^{2}\right.$, Table 1$)$ being only $\sim 22 \%$ smaller than the value measured by Ravishankara et al. $\left(1.76 \times 10^{-18} \mathrm{~cm}^{2}\right)$. One reason why our photolysisrelated partial lifetime is longer is that WACCM includes dif- fusive separation, which was not described in the earlier 2-D model study. The inclusion of diffusive separation reduces sharply the abundance of $\mathrm{SF}_{6}$ at high altitudes, where photolysis is most effective. Another contributing factor could be that the VUV photolysis is important only above $80 \mathrm{~km}$, while in our model runs $\mathrm{SF}_{6}$ is mostly destroyed by electron attachment, which results in less being transported into this upper-mesospheric region. When we analyse our WACCM $\mathrm{SF}_{6}$ tracer which is subject to photolysis loss only, the resulting steady-state overall lifetime (i.e. lifetime calculated using the rates of all loss processes) for the last model year (2007) is 17200 years, which is only $32 \%$ larger than the 
(a)
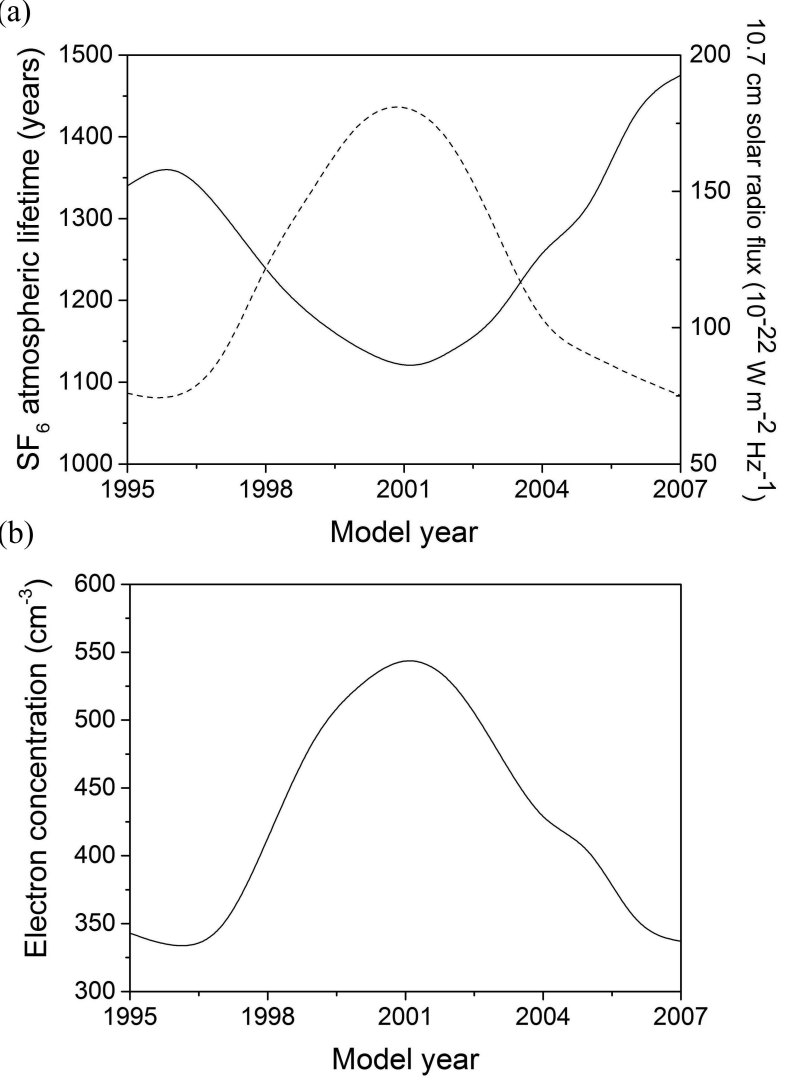

Figure 6. (a) Variation in atmospheric lifetime of $\mathrm{SF}_{6}$ (solid line) and $10.7 \mathrm{~cm}$ solar radio flux (dashed line) during the WACCM simulation. (b) Variation of the WACCM electron concentration $\left(\mathrm{cm}^{-3}\right)$ at $80 \mathrm{~km}$, averaged over polar latitudes $\left(60-90^{\circ} \mathrm{N}\right.$ and $\left.60-90^{\circ} \mathrm{S}\right)$.

value of Ravishankara et al. (1993) and thus more consistent with the difference in the Lyman- $\alpha$ cross sections. Finally, if we do not include the electron scaling factor to reduce the electron density below $80 \mathrm{~km}$ due to negative ion formation, then the $\mathrm{SF}_{6}$ lifetime decreases to 776 years (not shown), which is similar to the value of 800 years obtained by Morris et al. (1995).

\subsection{Impact of $\mathrm{SF}_{6}$ loss on mean age of stratospheric air}

As $\mathrm{SF}_{6}$ is a chemically stable molecule in the stratosphere and troposphere and has an almost linearly increasing tropospheric abundance, its atmospheric mixing ratio is often used to determine the mean age of stratospheric air. This is an important metric in atmospheric science as the distribution of ozone and other greenhouse gases depends significantly on the transport of air into, within, and out of the stratosphere. WACCM contains an idealized, linearly increasing age of air tracer (AOA1) that provides model age values for model experiments (Garcia et al., 2011).

Age of air has generally been derived from observations by treating $\mathrm{SF}_{6}$ as a passive (non-reactive) tracer. The assump- tion is that the global loss rate is too slow to significantly affect the lifetime. This was confirmed by Garcia et al. (2011) when only photolysis was included. However, when loss via electron attachment is also considered, the lifetime may become short enough that this assumption is no longer valid, in which case the stratospheric mixing ratio would appear to correspond to an earlier tropospheric mixing ratio than in reality. We have compared the passive $\mathrm{WACCM} \mathrm{SF}_{6}$ tracer with that subject to all loss processes, which yields the new lifetime of 1278 years. The difference between these two tracers indicates the error in the derived age of air that would arise in the real atmosphere if $\mathrm{SF}_{6}$ is assumed to be a passive tracer. The error caused by chemical removal can be expressed as

$\Delta(\mathrm{AoA})=\mathrm{AoA}($ reactive tracer $)-\mathrm{AoA}($ passive tracer $)$,

where $\Delta(\mathrm{AoA})$ is the difference in the age of air value caused by chemical loss, AoA(reactive tracer) is the calculated age of air considering the chemical removal and AoA (passive tracer) is the value obtained from a non-reactive tracer. The expression for the age of air at any point in the stratosphere can be obtained from a simplified version of (Eq. 1) that is derived from a Taylor series expansion, retaining only the linear term. It is then expressed as

$\mathrm{AoA}=\left[\left(\chi_{0}\left(\mathrm{SF}_{6}\right)-\chi\left(\mathrm{SF}_{6}\right)\right) / r\left(\mathrm{SF}_{6}\right)\right]$,

where $\chi\left(\mathrm{SF}_{6}\right)$ and $\chi_{0}\left(\mathrm{SF}_{6}\right)$ are the $\mathrm{SF}_{6}$ volume mixing ratios at the actual and the reference (tropical tropopause) points, respectively, while $r\left(\mathrm{SF}_{6}\right)$ is the rate of increase in tropospheric $\mathrm{SF}_{6}$. In our simulations $r\left(\mathrm{SF}_{6}\right)$ is $0.29 \mathrm{pptv} \mathrm{yr}^{-1}$ (Fig. 4), which is an approximation as the growth rate is not constant in reality. Stiller et al. (2012) report a value of $0.24 \mathrm{pptv} \mathrm{yr}^{-1}$ based on observations over the MIPAS period. These two simplifications will lead to deviations between WACCM and MIPAS age data. If Eq. (5) is substituted into Eq. (4) then the error in age of air will be

$\Delta(\mathrm{AoA})=\left(\chi\left(\mathrm{SF}_{6}\right.\right.$, passive $)-\chi\left(\mathrm{SF}_{6}\right.$, reactive $\left.)\right) / r\left(\mathrm{SF}_{6}\right)$.

This error, along with the mean age itself was calculated from WACCM output for 2007. Figure 7 shows the annual mean ages determined from the WACCM simulation from 2002 to 2007 using the total reactive and the inert $\mathrm{SF}_{6}$ tracers and the idealized AOA1 age tracer. There is a clear difference between the age values derived from the passive $\mathrm{SF}_{6}$ and the idealized AoA tracer. If Eq. (5) is used to determine the age values, there is no guarantee that the age values derived from the two tracers will be identical; the rate was determined from the increase in the $\mathrm{SF}_{6}$ burden $\left(0.29 \mathrm{pptv} \mathrm{yr}^{-1}\right)$ and this was provided by the linear fit (Fig. 4), which can misrepresent the growth rate at a specific time. Figure 7 also shows 
(a) WACCM-SF $F_{6}$ inert, 2002-2007

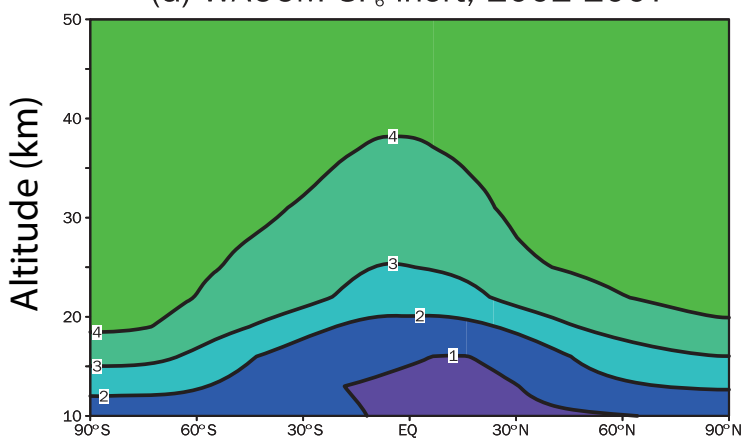

(c) WACCM - AOA, 2002-2007

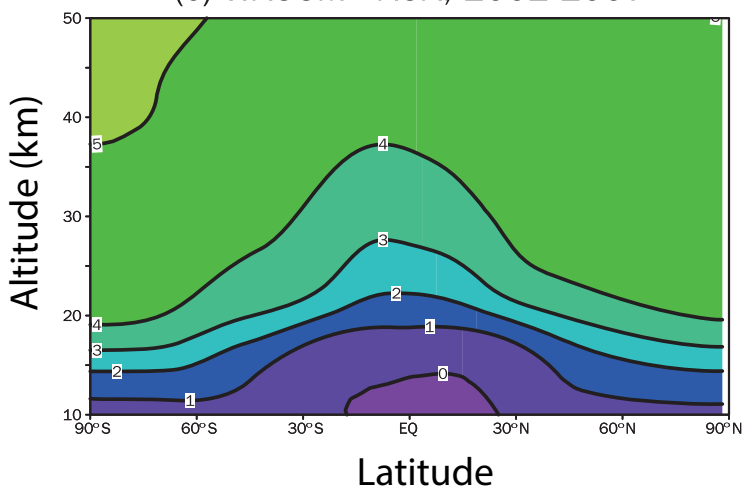

(b) WACCM-SF, 2002-2007

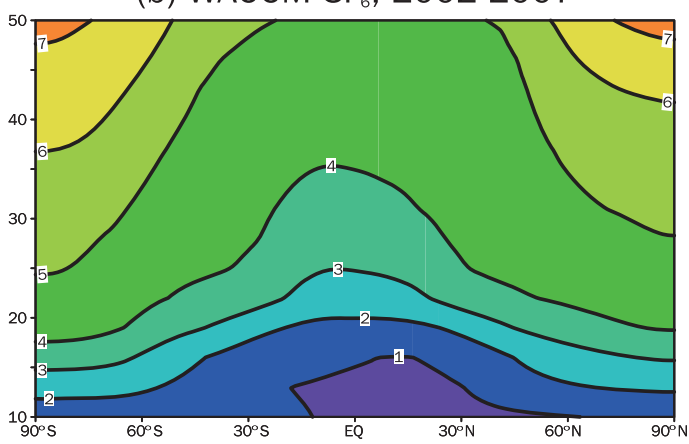

(d) MIPAS, 2002-2007

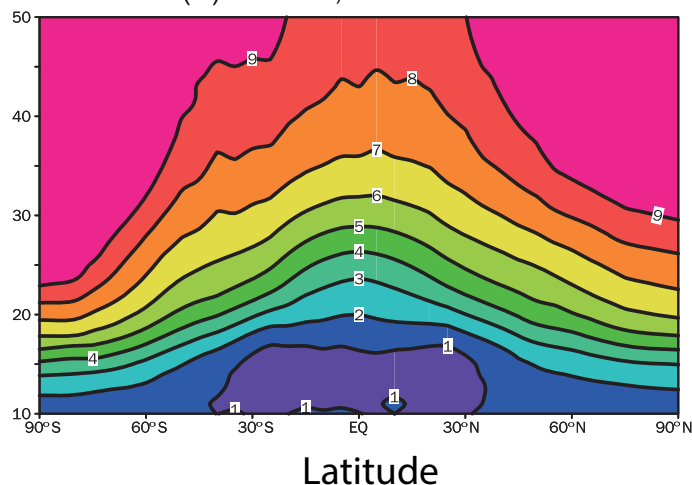

Figure 7. Annual mean age of stratospheric air (years) for the period of 2002-2007 determined from a WACCM simulation using (a) the inert $\mathrm{SF}_{6}$ tracer; (b) the total reactive $\mathrm{SF}_{6}$ tracer; (c) the idealized AOA1 tracer. Panel (d) shows the age values derived for the same period from our analysis of MIPAS $\mathrm{SF}_{6}$ observations.

Table 4. Integrated absorption cross sections for $\mathrm{SF}_{6}$ measured in this work and ratios with values obtained by GEISA (Gestion et Etude des Informations Spectroscopiques Atmosphériques; Jacquinet-Husson et al., 2011; Hurley, 2003; Varanasi, 2001) and HITRAN (HIgh-resolution TRANsmission molecular absorption database; Rothman et al., 2012).

\begin{tabular}{lrrrr}
\hline & & \multicolumn{3}{c}{$\begin{array}{l}\text { Ratio of integrated cross sections } \\
\text { in this work to previous studies }\end{array}$} \\
\cline { 3 - 5 } Band limits & $\begin{array}{r}\text { Integrated } \\
\left(\mathrm{cm}^{-1}\right)\end{array}$ & $\begin{array}{r}\text { Hurley } \\
\text { cross section } \\
\left(10^{-16} \mathrm{~cm}^{2}\right.\end{array}$ & $\begin{array}{r}\text { Varanasi } \\
(2003)\end{array}$ & HITRAN \\
& $\left.\mathrm{molec}^{-1} \mathrm{~cm}^{-1}\right)$ & & & \\
\hline $925-955$ & 2.02 & 1.07 & 1.01 & 0.99 \\
$650-2000$ & 2.40 & - & 1.09 & - \\
\hline
\end{tabular}

the difference between the age values obtained from the reactive and inert $\mathrm{SF}_{6}$ tracers. It can be seen that consideration of the reactive $\mathrm{SF}_{6}$ tracer does indeed affect the determined mean age values, mostly where electron attachment dominates. The age estimates at high latitudes are most sensitive to chemical loss because the air that reaches these locations has descended from the high altitudes where $\mathrm{SF}_{6}$ loss predominantly occurs. According to the MIPAS satellite observations
(Stiller et al., 2012; Haenel et al., 2015.), the derived age value over the tropical lower stratosphere at $25 \mathrm{~km}$ is slightly more than 3 years, while the WACCM simulations with the reactive $\mathrm{SF}_{6}$ tracer predicts 3 years. Comparing Fig. $7 \mathrm{a}$ and $\mathrm{b}$, the effect of chemical removal in this region is minor $(0.01$ year or $0.5 \%$ change), and therefore it does not have much impact on the inferred atmospheric transport. At the poles the effect is much more significant; the difference at $25 \mathrm{~km}$ between the reactive and inert $\mathrm{SF}_{6}$ tracers is up to 0.55 years $(9 \%)$. In summary, in the troposphere-stratosphere at low latitudes, the effect of chemical removal is not very significant and the error on the estimated mean age caused by the assumption of $\mathrm{SF}_{6}$ being a passive tracer is not important. However, the effect of chemical removal becomes more significant at high latitudes.

We can also compare modelled and observed mean age values in the lower stratosphere $(20 \mathrm{~km})$. Figure 8 shows the mean age profiles from WACCM tracers, ER-2 observations (Hall et al., 2009) and our analysis of MIPAS SF 6 satellite data at $20 \mathrm{~km}$. From this it can be seen that in the tropical region the mean age values are similar between the idealized age tracer and the inert and reactive $\mathrm{SF}_{6}$ tracers. This is consistent with no loss of $\mathrm{SF}_{6}$ having occurred in air parcels in the deep tropics. At high latitudes there is an up to 0.5-year 




Figure 8. Mean age values at $20 \mathrm{~km}$ altitude derived from MIPAS satellite (dashed magenta line) and ER-2 aircraft observations ( $\mathrm{SF}_{6}$ red open circles, $\mathrm{CO}_{2}$ black crosses; Hall et al., 1999). The error bars apply to the age derived from the ER-2 observations. Also shown is the mean age derived from WACCM tracers: reactive $\mathrm{SF}_{6}$ (dashed blue line), passive $\mathrm{SF}_{6}$ (light blue line) and AoA tracer (AOA1, solid green line).

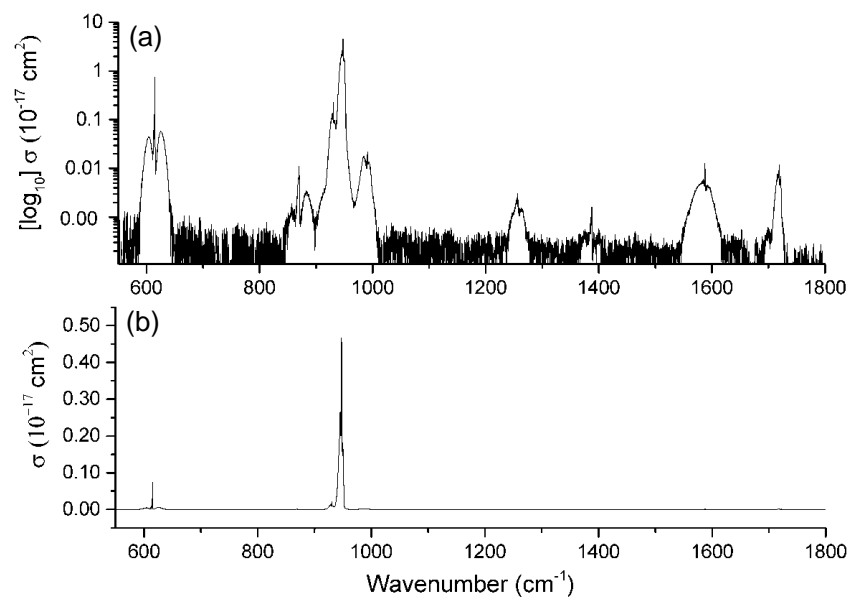

Figure 9. Infrared absorption spectrum of $\mathrm{SF}_{6}$ at $\sim 295 \mathrm{~K}$ on (a) a logarithmic $y$ axis and (b) a linear $y$ axis. The logarithmic scale in panel (a) highlights the relative positions of the minor bands.

difference in the modelled mean ages, with the reactive $\mathrm{SF}_{6}$ tracer producing the oldest apparent age. The differences in mean age between the tracers is larger in the $\mathrm{SH}$ polar region than in the NH because the polar region is less well mixed. The tendency is very similar when we compare the WACCM mean ages to the MIPAS observations. Note that the satellite

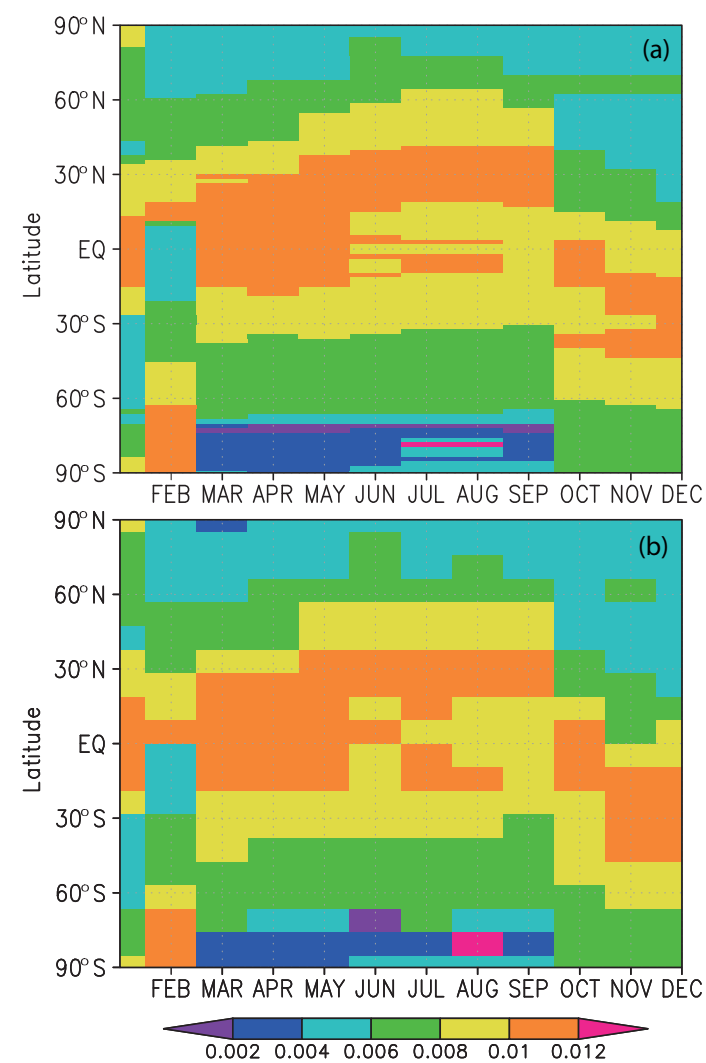

Figure 10. Latitude-time plots for instantaneous radiative forcing $\left(\mathrm{W} \mathrm{m}^{-2}\right)$ by $\mathrm{SF}_{6}$ as a function of latitude and month at (a) highlatitude resolution $\left(1.5^{\circ}\right.$ spacing $)$ and (b) low-latitude resolution $\left(9^{\circ}\right.$ spacing)

observations show more seasonal variability in the middle and high latitudes than in the tropics.

\subsection{Radiative efficiency and forcing}

To determine the radiative efficiency and global warming potential of $\mathrm{SF}_{6}$, integrated cross sections were taken from two public molecular spectroscopic databases: (i) the GEISA-2009/2011 (Gestion et Etude des Informations Spectroscopiques Atmosphériques) spectroscopic database (Jacquinet-Husson et al., 2011), which uses the data of Varanasi (2001) and Hurley (2003), and (ii) the HITRAN2012 (HIgh-resolution TRANsmission molecular absorption database) molecular spectroscopic database (Rothman et al., 2012), which uses the data of the Pacific Northwest National Laboratory Infra-Red Database (Sharpe et al., 2004). Values were also measured in this study. The literature values are presented in Table 4 for comparison with our experimentally determined values, and the full $\mathrm{SF}_{6}$ spectrum obtained in this study is given in Fig. 9. In our study the spectrometer error is $\pm 1.0 \%$ for all experiments, and the uncertainty in the sample concentrations of $\mathrm{SF}_{6}$ was calculated to be $0.7 \%$. Spectral noise was averaged at $\pm 5 \times 10^{-21} \mathrm{~cm}^{2}$ molecule ${ }^{-1}$ 
Table 5. Calculated instantaneous and stratospheric adjusted radiative forcings and radiative efficiencies of $\mathrm{SF}_{6}$ in clear and all-sky conditions.*

\begin{tabular}{lrrrrr}
\hline & \multicolumn{2}{c}{ Instantaneous } & & \multicolumn{2}{c}{ Stratospheric adjusted } \\
\cline { 2 - 3 } \cline { 6 - 7 } & Clear & All-sky & & Clear & All-sky \\
\hline Radiative forcing $\left(\mathrm{m} \mathrm{Wm}^{-2}\right)$ & 76.43 & 48.91 & & 81.81 & 56.01 \\
Radiative efficiency $\left(\mathrm{W} \mathrm{m}^{-2} \mathrm{ppbv}^{-1}\right)$ & 0.77 & 0.50 & & 0.85 & 0.59 \\
\hline
\end{tabular}

* Based on present day atmospheric $\mathrm{SF}_{6}$ surface concentration of 9.3 pptv.

Table 6. Comparison of 20-, 100- and 500-year global warming potentials for $\mathrm{SF}_{6}$ from this work with values from IPCC (2013).

\begin{tabular}{lrrr}
\hline & \multicolumn{3}{c}{ Global warming potential } \\
\cline { 2 - 4 } & $\mathrm{GWP}_{20}$ & $\mathrm{GWP}_{100}$ & $\mathrm{GWP}_{500}$ \\
\hline This work $^{\mathrm{a}}$ & 18000 & 23700 & 31300 \\
IPCC (2013) & 17500 & 23500 & $32600^{\mathrm{c}}$ \\
Difference (\%) & $+3 \%$ & $+1 \%$ & $-4 \%$ \\
(This work - IPCC) & & & \\
\hline
\end{tabular}

a Based on our atmospheric lifetime of 1278 years and radiative efficiency (RE) of $0.59 \mathrm{~W} \mathrm{~m}^{-2} \mathrm{ppbv}^{-1}$. ${ }^{\mathrm{b}}$ Based on an atmospheric lifetime of 3200 years and RE of $0.57 \mathrm{~W} \mathrm{~m}^{-2} \mathrm{ppbv}^{-1}$. ${ }^{\mathrm{c}}$ Based on an atmospheric lifetime of 3200 years and RE of $0.52 \mathrm{~W} \mathrm{~m}^{-2} \mathrm{ppbv}^{-1}$ from IPCC AR4 (Forster et al., 2007).

per $1 \mathrm{~cm}^{-1}$ band. However, at wavenumbers $<550 \mathrm{~cm}^{-1}$, towards the edge of the mid-infrared where opacity of the $\mathrm{KBr}$ optics increases, this value was $1 \times 10^{-20} \mathrm{~cm}^{2}$ molecule ${ }^{-1}$ per $1 \mathrm{~cm}^{-1}$ band. The error from determining the scaling cross section was $5 \%$. This results in an average overall error of $\pm 5 \%$ in the cross sections.

The intensities of the main $\mathrm{SF}_{6}$ absorption bands (925$955 \mathrm{~cm}^{-1}$ ) measured in this study are $7 \%$ greater than those reported by Hurley (2003), $1 \%$ greater than Varanasi (2001) and $1 \%$ lower than those given in HITRAN (Rothman et al., 2012; Table 4). Comparison of our results to Varanasi (2001) between 650 and $2000 \mathrm{~cm}^{-1}$ gives an agreement within $9 \%$. Note that these differences are within the combined error of both experiments.

The instantaneous and stratospheric adjusted $\mathrm{SF}_{6}$ radiative efficiencies in clear and cloudy-sky conditions are given in Table 5. These are also presented as present-day radiative forcings employing a current surface concentration of 9.3 pptv (NOAA, 2016; see Fig. 4). The radiative efficiency was calculated in the RFM for each month between $90^{\circ} \mathrm{S}$ and $90^{\circ} \mathrm{N}$ at latitudinal resolutions (on which the data were averaged to obtain the zonal mean vertical profile) of 1.5 and $9.0^{\circ}$. The tropopause used the standard WMO lapse rate definition (see Totterdill et al., 2016). Figure 10 shows the seasonal-latitudinal variation of the instantaneous clear-sky radiative forcing for $\mathrm{SF}_{6}$ on the high- $\left(1.5^{\circ}\right)$ and low- $\left(9^{\circ}\right)$ resolution grids. Employing profiles averaged over the lowerresolution grid gives an average forcing within $1 \%$ of the higher-resolution grid. Using only a single annually averaged global mean profile led to a $10 \%$ error in radiative forcing when compared to our monthly resolved high-resolution profile, supporting the findings of Freckleton et al. (1998) and Totterdill et al. (2016).

A selection of experiments were carried out over a range of months and latitudes to investigate the sensitivity of the forcing calculations to the bands used. The average contributions from the main bands were compared to the calculation with the full measured spectrum. The results showed that the 580-640 and $925-955 \mathrm{~cm}^{-1}$ bands contribute almost $99 \%$ to the instantaneous radiative forcing. Our forcing calculations suggest that the $\mathrm{SF}_{6}$ minor bands contribute only a small amount to the final value. This means that deviations between our experimentally determined spectra and those in the literature only result in a significant change to previously published radiative forcings and efficiencies when that deviation occurs over a major band.

The $\mathrm{SF}_{6}$ adjusted cloudy-sky radiative efficiency published by the IPCC AR5 report and used to determine its GWP values is $0.57 \mathrm{~W} \mathrm{~m}^{-2} \mathrm{ppbv}^{-1}$ (Myhre et al., 2013). This compares to our adjusted cloudy-sky radiative efficiency of $0.59 \mathrm{~W} \mathrm{~m}^{-2} \mathrm{ppbv}^{-1}$ (Table 5). A review on radiative efficiencies and global warming potentials by Hodnebrog et al. (2013) provides a comprehensive list of all published values for these parameters for many species including $\mathrm{SF}_{6}$. They established the range of published radiative efficiencies for $\mathrm{SF}_{6}$ to be $0.49-0.68 \mathrm{~W} \mathrm{~m}^{-2} \mathrm{ppbv}^{-1}$, with a mean value of $0.56 \mathrm{~W} \mathrm{~m}^{-2} \mathrm{ppbv}^{-1}$. They also made their own revised estimate using an average of the HITRAN (Rothman et al., 2012) and GEISA (Jacquinet-Husson et al., 2011) spectral databases and found a best estimate of $(0.565 \pm 0.025) \mathrm{W} \mathrm{m}^{-2} \mathrm{ppbv}^{-1}$. Their mean value for radiative efficiency is very close to that determined in this study using similar conditions $\left(0.59 \mathrm{~W} \mathrm{~m}^{-2} \mathrm{ppbv}^{-1}\right)$.

\subsection{Global warming potential}

Table 6 gives our estimates of the 20-, 100- and 500-year GWPs based on cloudy-sky adjusted radiative efficiencies of $\mathrm{SF}_{6}$ compared with IPCC AR5 values (IPCC, 2013). Our 20-, 100- and 500-year global warming potentials for $\mathrm{SF}_{6}$ are 18000,23800 and 31300 , respectively. The 20- and 100year values are $3 \%$ greater and $1 \%$ greater, respectively, 
than their IPCC counterparts, and the 500-year GWP is $4 \%$ smaller than its AR4 counterpart (Forster et al., 2007). The forcing efficiencies determined in this study are somewhat higher than the previously published values (see Sect. 3.4), which would imply a higher GWP value. However, our shorter atmospheric lifetimes would lead to a smaller GWP estimate, with a larger effect on longer time horizons when atmospheric loss becomes relevant. The trade-off between these competing effects is apparent in Table 6 , where $\mathrm{SF}_{6}$ exhibits a 20-year GWP that is slightly larger than the IPCC value, while the 500-year GWP is slightly smaller. The radiative efficiency effect is most obvious for the case of the 20year GWP where, because the atmospheric lifetime of $\mathrm{SF}_{6}$ is 1278 years, the species does not have time for any significant loss to occur.

\section{Conclusions}

The 3-D Whole Atmosphere Community Climate Model was used to simulate the $\mathrm{SF}_{6}$ atmospheric distribution over the period of 1995-2007. From the concentrations and the knowledge of the electron attachment, photolysis and metal reaction rates we determined the atmospheric lifetime, which shows a significant dependence $(-12$ to $+15 \%)$ on the solar cycle due to varying electron density. The mean $\mathrm{SF}_{6}$ atmospheric lifetime over a solar cycle was determined to be 1278 years (ranging from 1120 to 1475 years), which is different to previously reported literature values and much shorter than the widely quoted value of 3200 years. The reason is our more detailed treatment of electron attachment using a new formalism to describe both associative and dissociative attachment and the use of a detailed model of $D$ region ion chemistry to evaluate the partitioning of electrons and negative ions below $80 \mathrm{~km}$. Further refinement to this lifetime estimate from modelling studies depends on decadal length simulations of the model with detailed ion chemistry for the realistic long-term estimation of electron density in the upper atmosphere without the need for scaling factors as employed here.
Based on this new estimate of the $\mathrm{SF}_{6}$ lifetime, we find that the derived mean age of stratospheric air from observations can be slightly affected by the atmospheric removal of $\mathrm{SF}_{6}$. In the polar region the age of air values differ by up to $9 \%$ when the values from inert and reactive model tracers are compared, suggesting that $\mathrm{SF}_{6}$ loss does not have a large influence on the age values but that it should be included in detailed analyses.

We also reinvestigated the radiative efficiency and global warming potential of $\mathrm{SF}_{6}$. Our radiative efficiency value reported here, $0.59 \pm 0.045 \mathrm{~W} \mathrm{~m}^{-2} \mathrm{ppbv}^{-1}$, is slightly higher than the IPCC AR5 estimate of $0.57 \mathrm{~W} \mathrm{~m}^{-2} \mathrm{ppbv}^{-1}$. The global warming potentials of $\mathrm{SF}_{6}$ for 20,100 and 500 years have been determined to be 18000,23800 and 31300 , respectively. We find that our revised lifetime and efficiency values cancel each other out somewhat, so overall do not play a significant role in modifying the GWP estimates on these time horizons.

\section{Data availability}

The output from the WACCM experiments can be obtained by emailing Martyn Chipperfield. 


\section{Appendix A}

The climate metrics used in this paper are defined in the following ways.

Radiative forcing (RF) is the change in the net irradiance at the tropopause after allowing stratospheric temperatures to adjust to radiative equilibrium (expressed in watts per square metre; $\mathrm{Wm}^{-2}$ ) due to an internal or external change in the forcing of the climate system, such as a change in the concentration of $\mathrm{CO}_{2}$ or the output of the Sun.

Radiative efficiency (RE) is the radiative forcing per kilogram of compound.

Global warming potential (GWP) is defined by the expression

$\mathrm{GWP}=\frac{\int_{0}^{\mathrm{TH}} a_{\chi}[\chi(t)] \mathrm{d} t}{\int_{0}^{\mathrm{TH}} a_{r}[r(t)] \mathrm{d} t}$,

where $\mathrm{TH}$ is time horizon; $a_{\chi}$ is radiative forcing due to a unit increase in atmospheric abundance of the compound $\left(\mathrm{W} \mathrm{m}^{-2} \mathrm{~kg}^{-1}\right.$ ) and $[\chi(t)]$ is its time-dependent decay in concentration following its instantaneous release at time $t=0$. The denominator contains the corresponding quantities for $\mathrm{CO}_{2}$ as a reference gas (Myhre et al., 2013). GWP is the most common metric used by the WMO and IPCC to compare the potency of a greenhouse gas relative to an equivalent emission of $\mathrm{CO}_{2}$ over a set time period. GWP takes into account species lifetime. This means a species with a very high radiative forcing may still have a low GWP if it also possesses a short atmospheric lifetime. However, GWP does not account for factors such as changes in emission or the introduction of replacement species. Criticisms of GWP are discussed in greater detail by Myhre et al. (2013). 
Acknowledgement. This work was part of the MAPLE project funded by research grant NE/J008621/1 from the UK Natural Environment Research Council, which also provided a studentship for Anna Totterdill. The authors are also thankful to Jürgen Troe for helpful discussions related to the electron attachment to $\mathrm{SF}_{6}$. Martyn P. Chipperfield was supported by a Royal Society Wolfson Merit Award. Simulations were performed on the Archer and University of Leeds HPC systems.

Edited by: W. T. Sturges

Reviewed by: two anonymous referees

\section{References}

Bopp, J. C., Roscioli, J. R., Johnson, M. A., Miller, T. M., Viggiano, A. A., Villano, S. M., Wren, S. W., and Lineberger, W. C.: Spectroscopic characterization of the isolated $\mathrm{SF}_{6}(-)$ and $\mathrm{C}_{4} \mathrm{~F}_{8}(-)$ anions: Observation of very long harmonic progressions in symmetric deformation modes upon photodetachment, J. Phys. Chem. A, 111, 1214-1221, doi:10.1021/jp0665372, 2007.

Chabrillat, S. and Kockarts, G.: Simple parameterization of the absorption of the solar Lyman-alpha line, Geophys. Res. Lett., 24, 2659-2662, 1997.

Dlugokencky, E. J., Hall, B. D., Crotwell, M. J., Montzka, S. A., Dutton, G., Mühle, J., and Elkins, J. W.: Long-lived greenhouse gases, in: State of the Climate in 2015, B. Am. Meteorol. Soc., 97, S44-S46, 2016.

Dudhia, A.: Reference Forward Model V4.30, available at: http:// www.atm.ox.ac.uk/RFM (last access: 1 April 2016), 2013.

Edwards, D. P.: GENLN2: The new Oxford line-by-line atmospheric transmission/radiance model, Clarendon Laboratory, Oxford, 1987.

Eisfeld, W.: Highly accurate determination of the electron affinity of $\mathrm{SF}_{6}$ and analysis of structure and photodetachment spectrum of $\mathrm{SF}_{6}^{-}$, J. Chem. Phys., 134, 054303, doi:10.1063/1.3544213, 2011.

Freckleton, R. S., Highwood, E. J., Shine, K. P., Wild, O., Law, K. S., and Sanderson, M. G.: Greenhouse gas radiative forcing: Effects of averaging and inhomogeneities in trace gas distribution, Q. J. Roy. Meteorol. Soc., 124, 2099-2127, doi:10.1002/qj.49712455014, 1998.

Forster, P., Ramaswamy, V., Artaxo, P., Berntsen, T., Betts, R., Fahey, D. W., Haywood, J., Lean, J., Lowe, D. C., Myhre, G., Nganga, J., Prinn, R., Raga, G., Schulz, M., and Van Dorland, R.: Changes in Atmospheric Constituents and in Radiative Forcing, in: Climate Change 2007: The Physical Science Basis. Contribution of Working Group I to the Fourth Assessment Report of the Intergovernmental Panel on Climate Change, Cambridge University Press, Cambridge, United Kingdom and New York, NY, USA, 2007.

Garcia, R. R., Randel, W. J., and Kinnison, D. E.: On the determination of age of air trends from atmospheric trace species, J. Atmos. Sci., 68, 139-154, 2011.

Garcia, R. R., López-Puertas, M., Funke, B., Marsh, D. R., Kinnison, D. E., Smith, A. K., and Gomzález-Galindo, F.: On the distribution of $\mathrm{CO}_{2}$ and $\mathrm{CO}$ in the mesosphere and lower thermosphere, J. Geophys. Res., 119, 5700-5718, 2014.
Geller, L. S., Elkins, J. W., Lobert, J. M., Clarke, A. D., Hurst, D. F., Butler, J. H., and Myers, R. C.: Tropospheric SF 6 : Observed latitudinal distribution and trends, derived emissions and interhemispheric exchange time, Geophys. Res. Lett., 24, 675-678, 1997.

Haenel, F. J., Stiller, G. P., von Clarmann, T., Funke, B., Eckert, E., Glatthor, N., Grabowski, U., Kellmann, S., Kiefer, M., Linden, A., and Reddmann, T.: Reassessment of MIPAS age of air trends and variability, Atmos. Chem. Phys., 15, 13161-13176, doi:10.5194/acp-15-13161-2015, 2015.

Hall, T. M. and Plumb, R. A.: Age as a diagnostic of stratospheric transport, J. Geophys. Res., 99, 1059-1070, 1994.

Hall, T. M., Waugh, D. W., Boering, K. A., and Plumb, R. A.: Evaluation of transport in stratosphere models, J. Geophys. Res., 104, 18815-18839, 1999.

Harnisch, J. and Eisenhauer, A.: Natural $\mathrm{CF}_{4}$ and $\mathrm{SF}_{6}$ on Earth, Geophys. Res. Lett., 25, 2401-2404, 1998.

Hodnebrog, Ø., Etminan, M., Fuglestvedt, J. S., Marston, G., Myhre, G., Nielsen, C. J., Shine, K. P., and Wallington, T. J.: Global warming potentials and radiative efficiencies of halocarbons and related compounds: A comprehensive review, Rev. Geophys., 51, 300-378, doi:10.1002/rog.20013, 2013.

Hurley, M. D.: GEISA : 2011 Spectroscopic Database; SF 6 Infrared Absorption Cross-sections, 2003.

IPCC: Climate Change 2013: The Physical Science Basis, Contribution of Working Group I to the Fifth Assessment Report of the Intergovernmental Panel on Climate Change, Cambridge University Press, Cambridge, United Kingdom and New York, NY, USA, 1535 pp., 2013.

Jacquinet-Husson, N., Crepeau, L., Armante, R., Boutammine, C., Chédin, A., Scott, N. A., Crevoisier, C., Capelle, V., Boone, C., Poulet-Crovisier, N., Barbe, A., Campargue, A., Chris Benner, D., Benilan, Y., Bézard, B., Boudon, V., Brown, L. R., Coudert, L. H., Coustenis, A., Dana, V., Devi, V. M., Fally, S., Fayt, A., Flaud, J.-M, Goldman, A., Herman, M., Harris, G. J., Jacquemart, D., Jolly, A., Kleiner, I., Kleinböhl, A., Kwabia-Tchana, F., Lavrentieva, N., Lacome, N., Li-Hong, Xu, Lyulin, O.M., Mandin, J.-Y, Maki, A., Mikhailenko, S., Miller, C. E., Mishina, T., Moazzen-Ahmadi, N., H. S. P. Müller, A. Nikitin, J. Orphal, V. Perevalov,Perrin, D. T. Petkie, A. Predoi-Cross, Rinsland, C. P., Remedios, J. J., Rotger, M., Smith, M. A. H., Sung, K., Tashkun, S., Tennyson, J., Toth, R. A., Vandaele, A.-C., and Vander Auwera, J.: The 2009 edition of the GEISA spectroscopic database, J. Quant. Spectrosc. Ra., 112, 2395-2445, 2011.

Kovács, T., Plane, J. M. C., Feng, W., Nagy, T., Chipperfield, M. P., Verronen, P. T., Andersson, M. E., Newnham, D. A., Clilverd, M. A., and Marsh, D. R.: D region ion-neutral coupled chemistry (Sodankylä Ion Chemistry, SIC) within the Whole Atmosphere Community Climate Model (WACCM 4) - WACCMSIC and WACCM-rSIC, Geosci. Model Dev., 9, 3123-3136, doi:10.5194/gmd-9-3123-2016, 2016.

Lamarque, J.-F., Emmons, L. K., Hess, P. G., Kinnison, D. E., Tilmes, S., Vitt, F., Heald, C. L., Holland, E. A., Lauritzen, P. H., Neu, J., Orlando, J. J., Rasch, P. J., and Tyndall, G. K.: CAM-chem: description and evaluation of interactive atmospheric chemistry in the Community Earth System Model, Geosci. Model Dev., 5, 369-411, doi:10.5194/gmd-5-369-2012, 2012. 
Maiss, M. and Brenninkmeijer, C. A. M.: Atmospheric $\mathrm{SF}_{6}$, trends, sources and prospects, Environ. Sci. Technol., 32, 3077-3086, 1998.

Marsh, D. R., Mills, M. J., Kinnison, D. E., and Lamarque, J.F.: Climate change from 1850 to 2005 simulated in CESM1 (WACCM), J. Climate, 26, 7372-7391, 2013.

Mayer, B. and Kylling, A.: Technical note: The libRadtran software package for radiative transfer calculations - description and examples of use, Atmos. Chem. Phys., 5, 1855-1877, doi:10.5194/acp-5-1855-2005, 2005.

Meredith, N. P., Horne, R. B., Isles, J. D., and Rodriguez, J. V.: Extreme relativistic electron fluxes at geosynchronous orbit: Analysis of GOES E > $2 \mathrm{MeV}$ electrons, Space Weather, 13, 170-184, 2015.

Morris, R. A., Miller, T. M., Viggiano, A. A., Paulson, J. F., Solomon, S., and Reid, G.: Effects of electron and ion reactions on atmospheric lifetimes of fully fluorinated compounds, J. Geophys. Res., 100, 1287-1294, 1995.

Myhre, G., Shindell, D., Bréon, F.-M., Collins, W., Fuglestvedt, J., Huang, J., Koch, D., Lamarque, J.-F., Lee, D., Mendoza, B., Nakajima, T., Robock, A., Stephens, G., Takemura, T., and Zhang, H.: Anthropogenic and natural radiative forcing, Cambridge (UK), New York (USA), 2013.

NOAA Earth System Research Laboratory, Halocarbons and other atmospheric trace gases, $\mathrm{SF}_{6}$ - Combined Dataset, available at: http://www.esrl.noaa.gov/gmd/hats/combined/SF6.html, last access: 1 January 2016.

Plane, J. M. C., Feng, W., and Dawkins, E. C. M.: The mesosphere and metals, Chem. Rev., 115, 4497-4541, 2015.

Ravishankara, A. R., Solomon, S., Turnipseed, A. A., and Warren, R. F.: Atmospheric lifetimes of long-lived haloganated species, Science, 259, 194-199, 1993.

Reddmann, T., Ruhnke, R., and W. Kouker,W.: Three-dimensional model simulations of $\mathrm{SF}_{6}$ with mesospheric chemistry, J. Geophys. Res., 106, 14525-14537, doi:10.1029/2000JD900700, 2001.

Rothman, L. S., Gordon, I. E., Babikov, Y., Barbe, A., Benner, D. C., Bernath, P. F., Birk, M., Bizzocchi, L., Boudon, V., Brown, L. R., Campargue, A., Chance, K., Cohen, E. A., Coudert, L. H., Devi, V. M., Drouin, B. J., Faytl, A., Flaud, J. M., Gamache, R. R., Harrison, J. J., Hartmann, J. M., Hill, C., Hodges, J. T., Jacquemart, D., Jolly, A., Lamouroux, J., Roy, R. J. L., Li, G., Long, D. A., Lyulin, O. M., Mackie, C. J., Massie, S. T., Mikhailenko, S., Müller, H. S. P., Naumenko, O. V., Nikitin, A. V., Orphal, J., Perevalov, V., Perrin, A., Polovtseva, E. R., Richard, C., Smith, M. A. H., Starikova, E., Sung, K., Tashkun, S., Tennyson, J., Toon, G. C., Tyuterev, W. G., and Wagner, G.: The HITRAN 2012 Molecular Spectroscopic Database, J. Quant. Spectrosc. Ra., 130, 4-50, 2012.

Sharpe, S. W., Johnson, T. J., Sams, R. L., Chu, P. M., and Rhoderick, J. C.: Gas-Phase Databases for Quantitative Infrared Spectroscopy, Appl Spectrosc., 58, 1452-1461, 2004.
Stamnes, K., Tsay, S. C., Wiscombe, W., and Laszlo, I.: DISORT, a General-Purpose Fortran Program for Discrete-Ordinate-Method Radiative Transfer in Scattering and Emitting Layered Media: Documentation of Methodology, 2000.

Stiller, G. P., von Clarmann, T., Höpfner, M., Glatthor, N., Grabowski, U., Kellmann, S., Kleinert, A., Linden, A., Milz, M., Reddmann, T., Steck, T., Fischer, H., Funke, B., LópezPuertas, M., and Engel, A.: Global distribution of mean age of stratospheric air from MIPAS SF6 measurements, Atmos. Chem. Phys., 8, 677-695, doi:10.5194/acp-8-677-2008, 2008.

Stiller, G. P., von Clarmann, T., Haenel, F., Funke, B., Glatthor, N., Grabowski, U., Kellmann, S., Kiefer, M., Linden, A., Lossow, S., and López-Puertas, M.: Observed temporal evolution of global mean age of stratospheric air for the 2002 to 2010 period, Atmos. Chem. Phys., 12, 3311-3331, doi:10.5194/acp-12-33112012, 2012.

Tapping, K. E.: The $10.7 \mathrm{~cm}$ solar radio flux (F10.7), Space Weather, 11, 394-406, 2013.

Totterdill, A., Kovács, T., Gomez-Martin, J. C., Feng, W., and Plane, J. M. C.: Mesospheric removal of very long-lived greenhouse gases $\mathrm{SF}_{6}$ and $\mathrm{CFC}-115$ by metal reactions, Lyman- $\alpha$ photolysis, and electron attachment, J. Phys. Chem. A, 115, 2016-2025, 2015.

Totterdill, A., Kovács, T., Feng, W., Dhomse, S., Smith, C. J., Gómez-Martín, J. C., Chipperfield, M. P., Forster, P. M., and Plane, J. M. C.: Atmospheric lifetimes, infrared absorption spectra, radiative forcings and global warming potentials of NF3 and CF3CF2Cl (CFC-115), Atmos. Chem. Phys., 16, 11451-11463, doi:10.5194/acp-16-11451-2016, 2016.

Troe, J., Miller, T. M., and Viggiano, A. A.: Low-energy Electron Attachment to $\mathrm{SF}_{6}$ I., Kinetic modeling of nondissociative attachment, J. Chem. Phys., 127, 244303, 2007 a.

Troe, J., Miller, T. M., and Viggiano, A. A.: Low-energy electron attachment to $\mathrm{SF}_{6}$. II. Temperature and pressure dependences of dissociative attachment, J. Chem. Phys., 127, 244304, $2007 \mathrm{~b}$.

Varanasi, P.: $\mathrm{SF}_{6}$ Infrared Absorption Cross-Sections, available at: $2001 \mathrm{http}: / /$ ether.ipsl.jussieu.fr/ether/pubipsl/GEISA/geisa crossIR_frame_2011_uk.jsp (last access: 3 March 2015), 2001.

Verronen, P. T., Seppälä, A., Clilverd, M. A., Rodger, C. J., Kyrölä, E., Enell, C.-F., Ulich, T., and Turunen, E.: Diurnal variation of ozone depletion during the October-November 2003 solar proton events, J. Geophys. Res., 110, A09S32, doi:10.1029/2004JA010932, 2005.

Viggiano, A. A., Miller, T. M., Friedman, J. F., and Troe, J.: Lowenergy electron attachment to $\mathrm{SF}_{6}$. III. From thermal detachment to the electron affinity of $\mathrm{SF}_{6}$, J. Chem. Phys., 127, 244305, doi:10.1063/1.2804764, 2007.

Waugh, D. and Hall, T: Age of stratospheric air: Theory, observations and models, Rev Geophys., 40, 1010, doi:10.1029/2000RG000101, 2002. 